\title{
Sensitivity of secondary production and export flux to choice of trophic transfer formulation in marine ecosystem models
}

\author{
Thomas R. Anderson ${ }^{a, *}$, Dag O. Hessen ${ }^{b}$, Aditee Mitra $^{c}$, Daniel J. Mayor ${ }^{d}$, Andrew Yool $^{a}$
}

\footnotetext{
a National Oceanography Centre, University of Southampton, Waterfront Campus, Southampton SO14 3ZH, UK

${ }^{b}$ University of Oslo, Department of Biology, CEES, P.O. Box 1066 Blindern, 0316 Oslo, Norway

${ }^{c}$ Centre for Sustainable Aquatic Research, Wallace Building, Swansea University, Swansea SA2 8PP, UK

${ }^{d}$ Institute of Biological and Environmental Sciences, Oceanlab, University of Aberdeen, Main Street, Newburgh, Aberdeenshire AB416AA, UK

*: Corresponding author : Thomas R. Anderson, tel.: + 442380596337 ; email address : tra@noc.ac.uk
}

\begin{abstract}
:
The performance of four contemporary formulations describing trophic transfer, which have strongly contrasting assumptions as regards the way that consumer growth is calculated as a function of food $\mathrm{C}: \mathrm{N}$ ratio and in the fate of non-limiting substrates, was compared in two settings: a simple steadystate ecosystem model and a 3D biogeochemical general circulation model. Considerable variation was seen in predictions for primary production, transfer to higher trophic levels and export to the ocean interior. The physiological basis of the various assumptions underpinning the chosen formulations is open to question. Assumptions include Liebig-style limitation of growth, strict homeostasis in zooplankton biomass, and whether excess $\mathrm{C}$ and $\mathrm{N}$ are released by voiding in faecal pellets or via respiration/excretion post-absorption by the gut. Deciding upon the most appropriate means of formulating trophic transfer is not straightforward because, despite advances in ecological stoichiometry, the physiological mechanisms underlying these phenomena remain incompletely understood. Nevertheless, worrying inconsistencies are evident in the way in which fundamental transfer processes are justified and parameterised in the current generation of marine ecosystem models, manifested in the resulting simulations of ocean biogeochemistry. Our work highlights the need for modellers to revisit and appraise the equations and parameter values used to describe trophic transfer in marine ecosystem models.
\end{abstract}

Keywords: Ecosystem modelling ; Trophic transfer ; Stoichiometry ; Zooplankton

\section{Introduction}

Zooplankton are key players in the biogeochemical cycling of carbon and nutrients in marine ecosystems, especially in their roles in linking primary producers to higher trophic levels including fish (Beaugrand and Kirby, 2010 and Beaugrand et al., 2010) and in the export of organic matter to the deep ocean (e.g., González et al., 2009 and Juul-Pedersen et al., 2010). Parameterising zooplankton 
in models is however far from straightforward (Carlotti and Poggiale, 2010). Quantifying prey selectivity and ingestion is an important starting point given the role of zooplankton in top-down control of biomass stocks and so the functional response has received considerable attention (Gentleman et al., 2003 and Mitra and Flynn, 2006). Once ingested, food items are used for growth, with associated losses via faecal material and respiration/excretion. The role of food quality in trophic transfer provides an additional dimension which has been the subject of numerous experimental studies that have investigated the roles of nutrient elements (Augustin and Boersma, 2006, Jones et al., 2002 and Siuda and Dam, 2010) and biochemicals such as essential fatty acids (Burns et al., 2011 and Mayor et al., 2009a) as factors limiting growth and reproduction. Food quality may interact with food quantity (in terms of carbon), yet $\mathrm{C}$ may often be in stoichiometric excess when present in the food of herbivorous zooplankton to the extent that "leftover C" must be disposed of via faecal material or increased metabolic activity and respiration (Hessen and 
Anderson, 2008). These pathways for disposal have important implications for $\mathrm{C}$ cycling and C use efficiency of food webs as a whole (Hessen et al., 2004).

The theoretical basis of ecological stoichiometry has advanced considerably in recent years. Early models, with zooplankton as their focus, examined the potential for limitation by carbon versus nutrient elements, usually assuming that the latter can be used for growth with high efficiency whereas $\mathrm{C}$ is necessarily consumed in maintenance. Elemental ratios in grazer and food are used to calculate threshold elemental ratios (TERs) that, by definition, are the crossover from limitation by one element to another (Anderson, 1992; Hessen, 1992). In freshwater systems, phosphorus was identified as the element limiting the production of zooplankton, notably cladocerans, whereas nitrogen was generally believed to be limiting in marine systems (Elser and Hassett, 1994). A case can, however, be made for limitation by carbon if the energy requirements for maintenance are sufficiently high (Anderson and Hessen, 1995). Since these early models, stoichiometric theory has been extended to include biochemical compounds (Anderson and Pond, 2000), improved representation of bioenergetic costs such as protein synthesis and turnover (Anderson et al., 2005), analysis of maternal biomass (in addition to food) as a source of nutrition (Mayor et al., 2009b), and Dynamic Energy Budget approaches for describing how competing substrates are utilised subsequent to absorption by the gut (Kuijper et al., 2004). As well as considering how food quality impacts on zooplankton growth, stoichiometric models for use in ecosystem scenarios also need to consider the fate of nonlimiting elements. The main choice to make in this regard is whether elimination of substrates in stoichiometric excess occurs pre- or post-absorption by the gut. In the former case (e.g., DeMott et al., 1998), excess substrates are packaged within faecal material which may sink out of the euphotic zone and thereby contribute to export flux to the deep ocean. Conversely, post-absorptive regulation (e.g., Anderson et al, 2005) favours recycling in dissolved form. 
In the past, most marine ecosystem models, and particularly those running in general circulation models (GCMs), employed a single base currency (usually $\mathrm{N}$ or P) and, when necessary, converted to other currencies (notably C) by applying the Redfield ratio (e.g., Six and Maier-Reimer, 1996; Yamanaka and Tajika, 1997; Slagstad and Wassmann, 2001). With the realisation that many processes in marine food webs do not strictly conform to this ratio (especially for carbon versus nutrient elements, e.g., Anderson and Pondaven, 2003), models today often employ non-Redfield stoichiometry. For example, whereas a C:N ratio of 6.625 (Redfield) may be assigned to phytoplankton, alternate values are more appropriate for other state variables such as zooplankton, bacteria and the detritus. Appropriate parameterisations are then required to describe trophic transfer that take into consideration stoichiometric imbalances between predator and prey and how substrates in excess are dealt with. A wide range of such parameterisations is used in contemporary marine ecosystem models, begging the question as to whether predicted biogeochemical cycling is sensitive to this choice and, if so, the extent to which different choices can be justified in context of the experimental/observational literature.

Here, we compare the performance of four different trophic transfer formulations within two settings: (1) a simple steady-state ecosystem model, and (2) a 3D biogeochemical GCM (Yool et al., 2011). The four trophic transfer schemes are taken from: AH95 (Anderson and Hessen, 1995), ERSEM (European Regional Seas Ecosystem Model: Blackford et al., 2004), HadOCC (Hadley Centre Ocean Carbon Cycle model: Palmer and Totterdell, 2001) and Pah08 (Pahlow et al., 2008). The latter three are ecosystem models while the first, AH95, is the trophic transfer scheme used in the recently published MEDUSA (Model of Ecosystem Dynamics, nutrient Utilisation, Sequestration and Acidification) ecosystem model (Yool et al., 2011). Each has thus been implemented within ecosystem models and, as such, may be considered to be representative of the current state-of-the-art in this field. There is 
considerable variation in the assumptions underpinning the chosen transfer schemes (section 2) and, as a consequence, in the resulting predictions of transfer to higher trophic levels and carbon export (sections 3,4). Our aim is to highlight these differences and discuss them in context of the existing observational/experimental literature and the need for reliable parameterisations of non-Redfield stoichiometry in the next generation of marine ecosystem models.

\section{Trophic transfer schemes}

The metabolic budget of organisms, including different anabolic and metabolic requirements and how these are met from available substrates, needs to be taken into consideration when constructing trophic transfer formulations for use in ecosystem models.

Rules are required to govern the absorption of ingested substrates across the gut, limitation of growth in the face of variable elemental composition in food with associated losses via respiration and excretion, and for how remaining substrates in stoichiometric excess are dealt with. In this respect, the four trophic transfer formulations studied here, AH95, ERSEM, HadOCC and Pah08, vary markedly in their assumptions (Figure 1). Note that basal metabolic costs are not met directly using ingested substrates in any of these formulations but rather, when implemented in ecosystem models, a biomass-specific term is included as an additional loss rate. Within other, more recent, trophic transfer schemes (Anderson et al, 2005; Mitra 2006; Acheampong et al., 2012) ingested food is first and foremost allocated to basal metabolism, taking priority over other functions including growth. We considered including these formulations in the analysis here but, due to the radically different way that basal metabolism is represented, chose not to do so because it is difficult to achieve a fair comparison. Also, none of the four constructs used here consider the more complex issues of food quality and quantity discussed by Mitra and Flynn $(2005,2007)$ and Flynn (2009). 
125 Although undoubtedly important, the aim here is specifically to consider simpler model structures currently in use in marine ecosystem models, to illustrate how even minor differences can have significant impacts on the overall simulation. Our focus is thus on investigating model sensitivity to assumptions regarding how growth is limited by food quality $(\mathrm{C}: \mathrm{N})$ and for the fate of substrates in excess.

The four trophic transfer schemes (Figure 1) were initially set up using published parameter values. The objective is to compare functional forms and associated assumptions and so parameter values were adjusted, as far as possible, to be consistent with each other while remaining as faithful as possible to the originals. A fixed molar $\mathrm{C}: \mathrm{N}$ for zooplankton, $\theta_{\mathrm{Z}}$, of 5.5 (Gismervik, 1997) was set in each case, whereas food $\mathrm{C}: \mathrm{N}, \theta_{\mathrm{f}}$, was allowed to vary. Two changes to the published parameterisations were then made. First, excluding material voided as stoichiometric excess, all formulations were assigned a fixed absorption efficiency (AE) for $\mathrm{N}$ of 0.7 (e.g., Palmer and Totterdell, 2001, Blackford et al., 2004). Note that absorption efficiency is more commonly, but incorrectly, known as assimilation efficiency (assimilation is anabolism, the incorporation of absorbed digestive products into organismal tissue: Penry, 1998). For simplicity, carbon absorption efficiency was also set to 0.7 , otherwise additional rules would be required in some cases in order to deal with the imbalance. Second, with a C:N ratio of 6.625 (the Redfield ratio) for $\theta_{\mathrm{f}}$, parameter values were adjusted to achieve a gross growth efficiency (GGE) for $\mathrm{N}$ of 0.5 , which is close to the average of predicted efficiencies of $0.25,0.5,0.7$, and 0.6 for the AH95, ERSEM, HadOCC and Pah08 formulations respectively (after assigning fixed AE of 0.7). Bearing in mind these alterations, summary descriptions of the four trophic transfer schemes are as follows:

AH95: Stoichiometric regulation of homoeostasis in zooplankton biomass occurs postabsorption by the gut. After first calculating losses to faecal pellets from absorption efficiencies, either $\mathrm{C}$ or $\mathrm{N}$ in remaining substrates limits growth depending on specified 
maximum net production efficiencies, $k_{C}^{*}$ and $k_{N}^{*}$, of 0.3 and 1.0 respectively (in the case of $\mathrm{C}, 1-k_{C}^{*}$ is respired). If $\mathrm{C}$ and $\mathrm{N}$ are absorbed with equal efficiencies, the threshold elemental ratio (TER) occurs at $\theta_{Z} k_{N}^{*} / k_{C}^{*}$, i.e., the ideal food C:N is $>>\theta_{Z}$. The limiting element is utilised with maximum net production efficiency, with excess $\mathrm{C}$ or $\mathrm{N}$ respired or excreted in inorganic form. A complication is that absorption is calculated not in terms of $\mathrm{C}$ and $\mathrm{N}$, but rather nitrogenous compounds (proteins, assumed to have a fixed C:N of 3.96 and $\mathrm{AE}$ of 0.68 ) and non-nitrogenous compounds ( $\mathrm{C}$ only; $\mathrm{AE}=0.49$ ). This absorption scheme was replaced here with fixed AEs for $\mathrm{C}$ and $\mathrm{N}$ of 0.7 , as was also the case when the AH95 trophic transfer formulation was implemented in ecosystem models by Anderson and Pondaven (2003) and Yool et al., (2011). In order to achieve GGE for $\mathrm{N}$ of 0.5 (for $\theta_{\mathrm{f}}=6.625$ ), maximum zooplankton net production efficiency for $\mathrm{C}$ was increased from 0.3 to 0.593 . ERSEM. Unlike AH95, losses to faecal material are not deducted prior to calculating growth. The ideal $\theta_{\mathrm{f}}$ equals the body composition of the consumer such that $\mathrm{C}$ limits if $\theta_{\mathrm{f}}<\theta_{\mathrm{Z}}$ and $\mathrm{N}$ limits if $\theta_{\mathrm{f}}>\theta_{\mathrm{Z}}$. The limiting element is used with a fixed gross growth efficiency, $\mathrm{K}$, of 0.5 . Fraction 1-K is allocated according to parameters eu (0.9) and pdom (0.333), with 1-eu as inorganic release (respiration of $\mathrm{C}$ or excretion of $\mathrm{N})$, eu(1-pdom) as faecal material and eu.pdom as dissolved organic matter (DOM). The resulting absorption efficiency for the limiting element is $1-(\mathrm{eu}(1-\mathrm{pdom}))=0.7$. Equivalent fluxes are calculated for the nonlimiting element, proportional to $\theta_{\mathrm{Z}}$. Remaining $\mathrm{C}$ or $\mathrm{N}$ in stoichiometric excess is either allocated to faecal pellets in the case of C, or excreted as inorganic N. Note that the ecosystem models we use here do not include DOM, so the fluxes to DOM are instead assigned to inorganic nutrient and $\mathrm{CO}_{2}$.

HadOCC. As for ERSEM, the ideal $\theta_{\mathrm{f}}$ equals $\theta_{\mathrm{Z}}$. The limiting element is used with $\mathrm{K}=0.7$ with the remainder, 1-K, potentially allocated to detritus although there is a complication in 
that detritus is assumed to have a fixed $\mathrm{C}: \mathrm{N}$ ratio, $\theta_{\mathrm{D}}$, of 7.5. An imbalance occurs if this ratio differs from the $\mathrm{C}: \mathrm{N}$ of the consumer, in which case as much as possible of the $\mathrm{C}$ and $\mathrm{N}$ is allocated to detritus with the rest released as inorganic nutrient or $\mathrm{CO}_{2}$. Finally, excess $\mathrm{C}$ or $\mathrm{N}$ resulting from $\theta_{\mathrm{f}}$ being unequal to $\theta_{\mathrm{Z}}$ is similarly released as inorganic nutrient or $\mathrm{CO}_{2}$. For the purposes of the comparison here, parameter $\mathrm{K}$ was decreased from 0.7 to 0.5 .

Pah08. Again, ideal food $\mathrm{C}: \mathrm{N}$ equals $\theta_{\mathrm{Z}}$, but this time with $\mathrm{K}=0.9 . \mathrm{C}$ and $\mathrm{N}$ not assimilated into biomass, including excesses accruing from predator-prey stoichiometric imbalance, are allocated between DOM (fraction $f_{x}^{d}$ ) and egestion as faeces $\left(1-f_{x}^{d}\right)$, where parameter $f_{x}^{d}$ has a value of 0.25 . Absorption efficiency is thus 0.925 when consuming ideal prey, decreasing as excess $\mathrm{C}$ or $\mathrm{N}$ are present in the diet. In order to be consistent with the other transfer schemes, parameter $f_{x}^{d}$ was increased to 0.4 and $\mathrm{K}$ altered to 0.5 in order to give $\mathrm{AE}$ of 0.7 for ideal prey. As for ERSEM, fluxes to DOM were allocated to inorganic pools in the ecosystem models studied here.

It is worth noting that it was by no means trivial to set up the trophic transfer schemes by reading the published literature. In some instances, we contacted the original authors to ensure that our interpretation of their equations was correct. For the interested reader, we have put together an Excel spreadsheet in which each of the four formulations is set up in turn. This is available on request from the first author.

The predicted allocation of $\mathrm{N}$ and $\mathrm{C}$ between growth, excretion/respiration and faecal pellets, for each of the four trophic transfer schemes, is shown in Figure 2 for $\theta_{\mathrm{f}}$ between 4 and 20. The first point to note is that the ERSEM, HadOCC and Pah08 formulations all give identical predictions for GGEs for both $\mathrm{N}$ and $\mathrm{C}$ because they each assume that optimum $\theta_{\mathrm{f}}$ (the TER) equals $\theta_{Z}$ and then use a fixed GGE (0.5) for the limiting nutrient. Thus, N GGE is 0.5 for $\theta_{\mathrm{f}} \geq 5.5$ ( $\mathrm{N}$ limitation), whereas it reaches a value of 0.7 for $\theta_{\mathrm{f}} \geq 9.27$ in AH95 (the 
198

199

200

201

202

203

204

205

206

207

208

209

210

211

212

213

214

215

216

217

218

219

220

221

formulations were all parameterised to give $\mathrm{N} \mathrm{GGE}=0.5$ for $\theta_{\mathrm{f}}=6.625$ ). Excess $\mathrm{N}$ at a low $\theta_{\mathrm{f}}$ is excreted in inorganic form in all models, although in Pah08 a fraction of this $\mathrm{N}$ is also allocated to faecal material. Significant remineralisation of inorganic $\mathrm{N}$ occurs for all $\theta_{\mathrm{f}}$ in ERSEM and Pah08, but goes to zero in AH95 and HadOCC as absorbed substrates are used for growth with $100 \%$ efficiency. The HadOCC formulation allocates significantly more $\mathrm{N}$ to faecal pellets for $\theta_{\mathrm{f}} \geq 7.5$ as compared to the other trophic transfer schemes, 0.5 versus 0.3 . The patterns for allocation of $\mathrm{C}$ to respiration and faecal pellets are even more disparate. AH95 and ERSEM represent opposite ends of the spectrum, with excess C being respired in the former and allocated to faecal pellets in the latter. Pah08 is in between. The HadOCC formulation is constrained by the need to maintain a fixed $\mathrm{C}: \mathrm{N}$ in detritus (7.5) such that, at high $\theta_{\mathrm{f}}$, most $\mathrm{C}$ in food is respired. Overall, it is worth noting the strong asymmetry in allocation schemes for $\mathrm{C}$ and $\mathrm{N}$, and how this asymmetry varies between the different trophic transfer formulations.

Predicted GGEs for N and C are compared in Figure 3 with experimental data (Kiørboe, 1989) in which egg-producting female Acartia tonsa were fed the diatom Thalassiosira weissflogii with $\mathrm{C}$ : $\mathrm{N}$ ratios manipulated via nutrient concentrations in the algal medium (similar experimental results were found by Checkley (1980) for the copepod Paracalanus parvus). The decline in C GGE with increasing phytoplankton C:N predicted by the ERSEM trophic transfer formulation (and thereby also HadOCC and Pah08 which give the same result) shows good agreement with the data, a result of increasing severity of $\mathrm{N}$ limitation. The same trend is seen with the AH95 formulation, although it is slightly elevated relative to the data. In the case of $\mathrm{N}$, the constant N GGE of 0.5 (except at low $\theta_{\mathrm{f}}$ ) predicted by the ERSEM formulation lies slightly above the data, but is not unreasonable. The AH95 formulation, in contrast, predicts considerably higher N GGE. It would be harsh, however, to 
hastily condemn this model-data mismatch because it is hard to explain the low and more or less constant N GGE of $\sim 0.4$ seen in the data. One might expect $\mathrm{N}$ to be utilised for growth with high efficiency when it is limiting in the diet. Given typical AE for N of 0.6-0.9 (Hassett and Landry, 1988; Anderson, 1994), why are zooplankton apparently so wasteful in using it for growth? Maintenance costs, such as protein turnover, could be involved (e.g. Boersma and Kreutzer, 2002; Mayor et al., 2011), but it is as yet unclear as to whether these are sufficient in magnitude to significantly impact on overall growth efficiency.

\section{Steady state model}

\subsection{Model description}

A simple steady state ecosystem model of the euphotic zone was constructed in which each of the four trophic transfer schemes was implemented in turn. The transparency provided by the simplicity of the food web structure and associated parameterisation (other than trophic transfer, there are very few parameters) is justified in that the model is easy to understand and analyse. A purely theoretical approach is therefore appropriate in this instance (there is no attempt to compare with field data), although results will be discussed with reference to the results obtained using the $3 \mathrm{D}$ global GCM (section 4). As far as possible, the steady state and 3D models were made to be consistent in terms of ecosystem structure and parameterisation.

The food web model, which has both $\mathrm{C}$ and $\mathrm{N}$ as currencies, traces flows only, with no representation of stocks (Figure 4). Separation at pathway junctions is specified by linear parameterisations, permitting analytic solutions, which are presented for different values of phytoplankton $\mathrm{C}: \mathrm{N}$ ratio $\left(\theta_{\mathrm{P}}\right)$, to be readily obtained. The starting point of the model is new production (nitrate uptake) by phytoplankton $(\mathrm{P}), \mathrm{P}_{\mathrm{n}}$, against which subsequent flows within the food web are normalised. Carbon uptake associated with new production is $\theta_{\mathrm{P}} \mathrm{P}_{\mathrm{n}}$. New 
247 production is supplemented by regenerated production, $\mathrm{P}_{\mathrm{r}}$, accrued from ammonium (A)

248 regenerated within the food web. The grazer community in the model is separated into two

249 types: herbivores $(\mathrm{H})$, which graze $\mathrm{P}$, and an infinite chain of carnivores $(\mathrm{Z})$. Zooplankton are

250 often relatively homeostatic with respect to their biochemical composition (Andersen and

251 Hessen 1991) and so $\mathrm{H}$ and $\mathrm{Z}$ were assigned fixed $\mathrm{C}: \mathrm{N}$ ratios, $\theta_{\mathrm{H}}$ and $\theta_{\mathrm{Z}}$ respectively, of 5.5

252 (e.g., Gismervik, 1997). Two types of detritus are distinguished in the model, slow- and fast-

253 sinking $\left(D_{1}\right.$ and $D_{2}$, respectively), in similar fashion to other marine ecosystem models

254 (Leonard et al., 1999; Salihoglu et al., 2008; Yool et al., 2011). The former, which is largely

255 remineralised in the upper water column, is in the model derived from non-grazing

256 phytoplankton mortality (see below) and faecal pellet production by herbivores. Fast sinking

257 detritus results from carnivore faecal pellets. Given that the model is steady state, detritus

258 exported from the euphotic zone necessarily equals $\mathrm{P}_{\mathrm{n}}$.

259 Grazing usually dominates phytoplankton losses in marine ecosystems (Banse, 1994)

260 although other factors such as viral lysis may sometimes be important (Bratbak et al., 1990;

261 Thingstad, 2000). While faecal pellets may constitute a large part of the vertical flux to the

262 deep ocean (e.g., Honjo and Roman, 1978), material may also be exported in the form of

263 decaying phytoplankton as marine snow (Lampitt et al., 1993). The relative contribution of

264 pellet material to export remains incompletely understood (Turner, 2002). In the model, 68\%

265 of primary production is assumed to be grazed (parameter $\gamma=0.68$ ), this being the average

266 obtained from the base run of the 3D GCM (section 4). Similar values, 70\%, 73\% and 67\%

267 were obtained using biogeochemical ocean GCMs by Sarmiento et al (1993), Schmittner et

268 al. (2005) and Yool et al. (2011) respectively. The remaining non-grazing mortality, 1- $\gamma$, is

269 allocated directly to $\mathrm{D}_{1}$. Starting with the herbivores, a fixed fraction, $\phi$, of ingested material

270 is lost to ammonium. Parameter $\phi$ takes account of two processes. First, there is "messy 
271 feeding”, accounting for $20 \%$ of ingestion (Yool et al., 2011). Second, a fraction of intake is

272 allocated to meet the cost of basal metabolism. This is often specified as a biomass-specific

273 loss term in models but, as the steady state model does not include stocks, it is here related to

274 intake. If biomass-specific basal metabolism is $2 \% \mathrm{~d}^{-1}$ (Yool et al., 2011), intake is $1.0 \mathrm{~d}^{-1}$ and

275 growth efficiency is 0.5 , then $4 \%$ of intake is required (ideally, basal metabolic costs could be

276 deducted post-absorption, but for simplicity this is not the case here). Thus, $\phi=0.20+0.04=$

277 0.24. In the case of $\mathrm{N}$, remaining ingested material is processed with a fixed absorption

278 efficiency, $\beta_{\mathrm{HN}}$, with the remainder $\left(1-\beta_{\mathrm{HN}}\right)$ lost as faecal material to detritus $\left(\mathrm{D}_{1}\right)$. The

279 absorbed substrates are then used for growth with a fixed net production efficiency, $\mathrm{k}_{\mathrm{HN}}$, with

$280\left(1-\mathrm{k}_{\mathrm{HN}}\right)$ excreted as ammonium. Following the same principles, $\beta_{\mathrm{ZN}}$ and $\mathrm{k}_{\mathrm{ZN}}$ quantify trophic

281 transfer of $\mathrm{N}$ by carnivorous zooplankton, and commensurate $\mathrm{C}$ flows are specified by $\beta_{\mathrm{HC}}$ and $\mathrm{k}_{\mathrm{HC}}$ (herbivores) and $\beta_{\mathrm{ZC}}$ and $\mathrm{k}_{\mathrm{ZC}}$ (carnivores). Values for the $\beta_{\mathrm{i}}$ and $\mathrm{k}_{\mathrm{i}}$ parameters are taken from the allocations to $\mathrm{C}$ and $\mathrm{N}$ as a function of $\theta_{\mathrm{f}}$ as shown in Figure 2. Detritus (sinking particles) is either exported from the euphotic zone, fractions $\zeta_{1}$ and $\zeta_{2}$ for slow- and fast-sinking respectively, or remineralised as ammonium. Parameters $\zeta_{1}$ and $\zeta_{2}$ were assigned values from the base run of the 3D model (section 4), giving $\zeta_{1}=0.27$ and $\zeta_{2}=0.68$.

An advantage of using a simple linear approach to parameterisation is that it is straightforward to provide equations that describe the steady state solution of the model. Production by herbivores, $\mathrm{G}_{\mathrm{H}}$, is:

290

$$
\mathrm{G}_{\mathrm{H}}=\gamma(1-\phi) \beta_{\mathrm{HN}} \mathrm{k}_{\mathrm{HN}}\left(\mathrm{P}_{\mathrm{n}}+\mathrm{P}_{\mathrm{r}}\right)
$$

291 The associated export flux via $\mathrm{D}_{1}, \mathrm{Ex}_{\mathrm{D} 1(\mathrm{~N})}$, needs to take into consideration the fraction of phytoplankton lost to non-grazing mortality, $1-\gamma$, and the fact that only fraction $\zeta_{1}$ of $\mathrm{D}_{1}$ produced is exported:

$$
\operatorname{Ex}_{\mathrm{D} 1(\mathrm{~N})}=\zeta_{1}\left((1-\gamma)+\gamma(1-\phi)\left(1-\beta_{\mathrm{HN}}\right)\right)\left(\mathrm{P}_{\mathrm{n}}+\mathrm{P}_{\mathrm{r}}\right)
$$


295

296

297

298

299

300

301

302

303

304

305

306

307

308

309

310

311

The equivalent terms for production of carnivores and associated export via $D_{2}, G_{Z}$ and

$\mathrm{Ex}_{\mathrm{D} 2(\mathrm{~N})}$, are calculated on the basis that carnivores are ordered into an infinite chain:

$$
\mathrm{G}_{\mathrm{Z}}=\mathrm{G}_{\mathrm{H}} \sum_{i=1}^{\infty}\left((1-\phi) \beta_{\mathrm{ZN}} \mathrm{k}_{\mathrm{ZN}}\right)^{\mathrm{i}}=\mathrm{G}_{\mathrm{H}}\left(\mathrm{f}\left[(1-\phi) \beta_{\mathrm{ZN}} \mathrm{k}_{\mathrm{ZN}}\right]-1\right)
$$

$$
\begin{aligned}
\operatorname{Ex}_{\mathrm{D} 2(\mathrm{~N})} & =\zeta_{2} \mathrm{G}_{\mathrm{H}}(1-\phi)\left(1-\beta_{\mathrm{ZN}}\right) \sum_{i=0}^{\infty}\left((1-\phi) \beta_{\mathrm{ZN}} \mathrm{k}_{\mathrm{ZN}}\right)^{\mathrm{i}} \\
& =\zeta_{2} \mathrm{G}_{\mathrm{H}}(1-\phi)\left(1-\beta_{\mathrm{ZN}}\right) \mathrm{f}\left[(1-\phi) \beta_{\mathrm{ZN}} \mathrm{k}_{\mathrm{ZN}}\right]
\end{aligned}
$$

where function $\mathrm{f}[\mathrm{x}]$ is:

$$
\mathrm{f}[\mathrm{x}]=\sum_{i=0}^{\infty} x^{i}=1 /(1-\mathrm{x}), 0<\mathrm{x}<1
$$

Corresponding terms for export of $\mathrm{C}, \mathrm{Ex}_{\mathrm{D} 1(\mathrm{C})}$ and $\mathrm{Ex}_{\mathrm{D} 2(\mathrm{C})}$, are:

$$
\begin{aligned}
& \operatorname{Ex}_{\mathrm{D} 1(\mathrm{C})}=\zeta_{1}\left((1-\gamma)+\gamma(1-\phi)\left(1-\beta_{\mathrm{HC}}\right)\right) \theta_{\mathrm{P}}\left(\mathrm{P}_{\mathrm{n}}+\mathrm{P}_{\mathrm{r}}\right) \\
& \operatorname{Ex}_{\mathrm{D} 2(\mathrm{C})}=\zeta_{2} \theta_{\mathrm{H}} \mathrm{G}_{\mathrm{H}}(1-\phi)\left(1-\beta_{\mathrm{ZC}}\right) \mathrm{f}\left[(1-\phi) \beta_{\mathrm{ZC}} \mathrm{k}_{\mathrm{ZC}}\right]
\end{aligned}
$$

All that remains is to calculate regenerated production, $\mathrm{P}_{\mathrm{r}}$. The fate of nitrogen (nitrate or ammonium) consumed in primary production is either to be exported and lost from the system, or recycled to the ammonium pool from where it starts its journey round the food web again. The probability of the latter, $\mathrm{p}_{\mathrm{A}}$, is:

$$
\mathrm{p}_{\mathrm{A}}=1-\left(\mathrm{Ex}_{\mathrm{D} 1(\mathrm{~N})}+\mathrm{Ex}_{\mathrm{D} 2(\mathrm{~N})}\right) /\left(\mathrm{P}_{\mathrm{n}}+\mathrm{P}_{\mathrm{r}}\right)
$$

Replacing the terms in the above equation with those in Eqs. (1), (2) and (4), and rearranging, gives:

$$
\mathrm{p}_{\mathrm{A}}=1-\zeta_{1}\left((1-\gamma)+\gamma(1-\phi)\left(1-\beta_{\mathrm{HN}}\right)\right)-\zeta_{2} \gamma(1-\phi) \beta_{\mathrm{HN}} \mathrm{k}_{\mathrm{HN}}(1-\phi)\left(1-\beta_{\mathrm{ZN}}\right) \mathrm{f}\left[(1-\phi) \beta_{\mathrm{ZN}} \mathrm{k}_{\mathrm{ZN}}\right]
$$

$\mathrm{P}_{\mathrm{r}}$ is then calculated by taking into account repeated recycling of $\mathrm{N}$ by the food web:

$$
\mathrm{P}_{\mathrm{r}}=\mathrm{P}_{\mathrm{n}}\left[\mathrm{p}_{\mathrm{A}}+\mathrm{p}_{\mathrm{A}}^{2}+\mathrm{p}_{\mathrm{A}}^{3}+\mathrm{p}_{\mathrm{A}}^{4}+\ldots\right]=\mathrm{P}_{\mathrm{n}}\left(\mathrm{f}\left[\mathrm{p}_{\mathrm{A}}\right]-1\right)
$$


317 Results are presented showing how predicted nutrient cycling and export relate to

318 phytoplankton $\mathrm{C}: \mathrm{N}$ ratio. While the canonical Redfield ratio may be representative of

319 autotroph cell growth under optimum conditions (Geider and La Roche, 2002; Finkel et al.,

320 2010), it is known that phytoplankton C:N can strongly differ from Redfield (e.g., Daly et al.,

321 1999; Sterner et al., 2008; Flynn, 2010). Values double or treble the Redfield ratio can occur

322 in response to high light and/or low nutrient conditions (Dickman et al., 2006; Hessen et al.,

323 2008). It is also worth noting that phytoplankton at times make up a modest fraction of seston

324 (Frigstad et al., 2011) and when zooplankton feed on seston of mixed origin they may face

325 major deviations in food stoichiometry. We chose to analyse model solutions for $\theta_{\mathrm{P}}$ between

3264 and 20.

327 Results of the steady state model are shown in Figure 5, in all cases normalised against

328 external $\mathrm{N}$ input to the system (i.e., $\mathrm{P}_{\mathrm{n}}=1$ ). Primary production drives the food web and, new

329 and regenerated production summed together, reaches 4 to 6 and is thus dominated by $\mathrm{P}_{\mathrm{r}}$ (Fig.

330 5a). Equivalent $f$-ratios are $\sim 0.15$ to 0.25 , similar to those estimated for ocean systems

331 (Eppley and Peterson, 1979). Three sources of recycling of $\mathrm{N}$ contribute to regenerated

332 production in the model: direct release by grazers via messy feeding and basal metabolism

333 (parameter $\phi)$, excretion by grazers $\left(1-\mathrm{k}_{\mathrm{N}}\right)$ and remineralisation of detritus $(1-\zeta)$, accounting

334 for approx. 30-40\%, 20-30\% and 40-50\% of ammonium release respectively (except for the

335 HadOCC version where excretion by grazers and remineralisation of detritus levelled off at

$3366 \%$ and $60 \%$ respectively at high $\theta_{\mathrm{P}}$ ). Of the detritus produced, approx. $45 \%$ is from non-

337 grazing phytoplankton mortality, with the remainder as faecal pellets. The variation seen in

338 total primary production is mainly due to the excretion term such that the ERSEM and Pah08

339 model versions predict the highest primary production at high $\theta_{\mathrm{P}}$ because these two

340 formulations exhibit significant excretion even when $\mathrm{N}$ is limiting production (Fig. 2a). All 
341 models show increasing primary production when herbivores are limited by $\mathrm{C}$ (low $\theta_{\mathrm{P}}$, less

342 than the TER) as herbivores excrete the non-limiting element, $\mathrm{N}$, which is in excess.

343 Herbivore production, which depends jointly on N GGE and total primary production (Eq.

344 1), shows considerable variation between the different model versions (Fig. 5b). It increases

345 with increasing $\theta_{\mathrm{P}}$ under $\mathrm{C}$-limiting conditions $\left(\theta_{\mathrm{P}}<\mathrm{TER}\right)$ as $\mathrm{N}$ is progressively used with

346 greater efficiency and excretion of excess $\mathrm{N}$ diminishes. At high $\theta_{\mathrm{P}}$, the greatest $\mathrm{N}$ GGE is

347 associated with the AH95 trophic transfer formulation (Fig. 2a), giving rise to the highest

348 predicted $\mathrm{G}_{\mathrm{H}}$ of 1.72 . In contrast, herbivore production is only 1.10 when using the HadOCC

349 model version, lower than 1.34 for ERSEM and Pah08, but not because of lower N GGE

350 (these three trophic transfer formulations give rise to the same N GGE: Fig. 2a), but rather

351 because it has the lowest primary production (Fig. 5a). In the case of carnivores, there is no

352 direct influence of $\theta_{P}$ on $G_{Z}$ but, rather, $G_{Z}$ depends on $G_{H}$ and GGE (Eq. 3). Thus, the trends

353 seen in carnivore production mirror those for herbivores (Fig. 5c) although the ERSEM

354 model version exhibits higher production than AH95 because the N GGE for $\theta_{\mathrm{f}}=5.5$ (the

355 C:N of prey) is higher (0.5 vs. 0.42$)$.

356 As for secondary production, large differences in predicted export are seen when using the

357 different trophic transfer formulations. Total carbon export, and its variation with $\theta_{\mathrm{P}}$, is

358 dominated by the slow-sinking fraction (Fig. 5d, f), emphasising the importance of correctly

359 parameterising herbivore stoichiometry and associated trophic transfer in models. Greatest

360 carbon export is associated with the ERSEM and Pah08 model versions as excess C

361 generated at high $\theta_{\mathrm{P}}$ is allocated to herbivore faecal pellets, whereas in the other versions

362 some or all of the excess $\mathrm{C}$ is respired to $\mathrm{CO}_{2}$. It is interesting to note how predicted $\mathrm{C}$ export

363 is decoupled from the trophic transfer of $\mathrm{N}$. Unlike the export of $\mathrm{N}$ which is constrained in

364 that $\mathrm{Ex}_{\mathrm{D} 1(\mathrm{~N})}+\mathrm{Ex}_{\mathrm{D} 2(\mathrm{~N})}=\mathrm{P}_{\mathrm{n}}$, the same is not true for $\mathrm{C}$, i.e., $\mathrm{Ex}_{\mathrm{D} 1(\mathrm{C})}+\mathrm{Ex}_{\mathrm{D} 2(\mathrm{C})}$ does not 
365

necessarily equal $\theta_{\mathrm{P}} \mathrm{P}_{\mathrm{n}}$. In fact, this result is not surprising as pe-ratio (export of organic carbon/primary production: Dunne et al., 2005) only equals $f$-ratio (in steady state) if there are no stoichiometric imbalances in the system. If the $\mathrm{C}: \mathrm{N}$ of detritus exceeds that of phytoplankton, which may be expected if $\mathrm{C}$ absorption efficiency is less than that for nutrient elements (e.g., Mayor et al., 2011), then C export will exceed that fixed in new production, $\theta_{\mathrm{P}} \mathrm{P}_{\mathrm{n}}$. The C:N ratio of exported detritus does indeed exceed that of phytoplankton in the model predictions derived using the ERSEM trophic transfer formulation (except for $\theta_{\mathrm{P}}=5.5$, when the two are equal) due to allocation of excess $\mathrm{C}$ to faecal pellets. It is perhaps more surprising that, at high $\theta_{\mathrm{P}}$, the $\mathrm{C}: \mathrm{N}$ ratio of export is lower than $\theta_{\mathrm{P}}$ when using the AH95 and HadOCC trophic transfer formulations, a result of excess $\mathrm{C}$ being respired to $\mathrm{CO}_{2}$. The $\mathrm{C}: \mathrm{N}$ of particulate organic matter is remarkably constant in the marine systems (Chen et al, 1996), close to the Redfield ratio. If excess $\mathrm{C}$ in phytoplankton is respired to $\mathrm{CO}_{2}$ this may, to some extent, buffer the system against variability in phytoplankton $\mathrm{C}: \mathrm{N}$.

Although fast-sinking detritus represents only a minor fraction of the total export, parameterising it accurately in models is important because it reaches great depths. Unlike $\mathrm{D}_{1}$, the $\mathrm{C}: \mathrm{N}$ ratio of this fraction is not directly related to $\theta_{\mathrm{P}}$ but is instead proportional to herbivore production, $\mathrm{G}_{\mathrm{H}}$ (Fig. 5e). It therefore shows the same trends as $\mathrm{G}_{\mathrm{Z}}$ versus $\theta_{\mathrm{P}}$ (Fig. 5c), although inverted in terms of magnitude (HadOCC highest, ERSEM lowest). Thus, herbivores dampen the system by ironing out stoichiometric imbalances associated with phytoplankton $\mathrm{C}: \mathrm{N}$, but parameterisation of carnivores is also important because this determines the proportionality between $\mathrm{G}_{\mathrm{H}}$ and export of $\mathrm{D}_{2}$.

\section{3D General circulation model}

4.1. Methodology 
A new ecosystem model, MEDUSA-1.0 (Model of Ecosystem Dynamics, nutrient

390

Utilisation, Sequestration and Acidification; henceforth MEDUSA) was recently used in a multi-decadal hindcast simulation in the NEMO (Nucleus for European Modelling of the Ocean) global GCM (Yool et al., 2011). We compare the performance of the different trophic transfer formulations in this biogeochemical GCM, after making modifications to the parameterisation of trophic transfer in MEDUSA to provide consistency with the steady-state model.

MEDUSA is an intermediate complexity ecosystem model, specifically designed for the global domain, which divides the food web into "small" and "large" portions (Fig. 6). Size structure may be expected to affect the relationship between primary production, secondary production and export, with greater transfer of carbon to higher trophic levels in systems dominated by large organisms ordered in short food chains (Michaels and Silver, 1988). Nanophytoplankton and microzooplankton dominate the small fraction, together with slowsinking detritus particles. The large portion includes diatoms and mesozooplankton, together with large detritus particles that are afforded an implicit representation because of their fast sinking rate. Phytoplankton chlorophyll is explicitly represented, permitting photoacclimation of C:chl in response to ambient light. Nitrogen is the base currency of the model, with the biogeochemical cycles of silicon and iron also included. Slow sinking detritus is produced via mortality of non-diatom phytoplankton and microzooplankton faecal pellets. It sinks at a speed of $3 \mathrm{~m} \mathrm{~d}^{-1}$ and is subject to both remineralisation and grazing by micro- and mesozooplankton. Fast sinking detritus is derived from mortality of diatoms and faecal pellet production by mesozooplankton. It is not modelled explicitly but rather, at each time step, production of large particles is instantly remineralised through the vertical levels of the model based on the ballast theory of Armstrong et al. (2002). For a full description of MEDUSA, including a comprehensive list of equations and parameter values, see Yool et al. (2011). 
414 The trophic transfer scheme used in MEDUSA, as published in Yool et al (2011), is 415 AH95, including fixed absorption efficiencies for C and N. Although C is not explicitly 416 represented as a model currency, phytoplankton and zooplankton are assigned (fixed) C: N 417 ratios for the purpose of calculating trophic transfer (the model run described in Yool et al. 418 (2011) assigned the Redfield ratio of 6.625 to each). Other associated parameter values used by Yool et al. (2011) are $\beta_{\mathrm{N}}=\beta_{\mathrm{C}}=0.69$ (Anderson, 1994) and $\mathrm{k}_{\mathrm{C}}=0.80$ (Anderson and Pondaven, 2003). For the purpose of intercomparison of the trophic transfer schemes, and to provide consistency with the steady state model, these parameters were reassigned values as for AH95 (section 2), i.e. $\beta_{N}=\beta_{C}=0.70, k_{C}=0.593$ and $\theta_{Z}=5.5$. In addition to these changes in model parameter values, one alteration was made to the formulation of grazing in order to provide consistency with the steady-state model. In MEDUSA, as published in Yool et al. (2011), microzooplankton graze on non-diatoms and slow sinking detritus while mesozooplankton consume non-diatoms, diatoms, microzooplankton and slow-sinking detritus. As there was no grazing by zooplankton on detritus in the steady state model, we therefore reconfigured the flow pathways in MEDUSA to remove grazing on detritus, maintaining proportionality in prey preference parameters for remaining prey items (Fig. 6). Furthermore, MEDUSA does not have a state variable for detritus C. Trophic transfer and associated ecosystem dynamics are not compromised by this omission as there is no feedback between detritus $\mathrm{C}$ and ecosystem functioning. Model predictions for export are therefore quantified, and compared for the different trophic transfer formulations, in $\mathrm{N}$ units. whereas model solutions for a wide range of phytoplankton $\mathrm{C}: \mathrm{N}$ ratios were investigated with the steady-state model, the 3D study investigated only $\theta_{\mathrm{P}}=6.625$ (the Redfield ratio). 
439

440

441

442

443

444

445

446

447

and microzooplankton and so food quality is variable, $5.5 \leq \theta_{\mathrm{f}} \leq 6.625$. The model ecosystem is driven by $\mathrm{N}$ and so it is the difference in $\mathrm{N}$ allocation schemes (Fig. 2a; values for $\theta_{\mathrm{f}}=5.5$, 6.625 listed in Table 1) that is significant for simulated ecosystem dynamics. In this regard, the ERSEM and Pah08 trophic transfer formulations are exactly equivalent for this range of food $\mathrm{C}: \mathrm{N}$ and so the work therefore involves a 3-way comparison where MEDUSA (incorporating AH95) is compared with simulations in which the AH95 trophic transfer scheme is replaced in turn by ERSEM/Pah08 and HadOCC (parameterised as in section 2). Points to note from Table 1 are: (1) N GGE for $\theta_{\mathrm{f}}=6.625$ is the same (0.5) for all the transfer schemes; (2) AH95 and ERSEM are identical for $\theta_{\mathrm{f}}=6.625$, but differ for $\theta_{\mathrm{f}}=5.5$ (microzooplankton as prey) with lower growth efficiency (0.42 vs. 0.5$)$ and higher nutrient regeneration (0.28 vs. 0.2$)$ in $\mathrm{AH} 95 ;(3)$ allocation to faecal pellets is highest, and excretion of nutrient lowest, with the HadOCC trophic transfer formulation and, furthermore, this occurs for both $\theta_{\mathrm{f}}=5.5,6.625$ (and thus will come into play when both microzooplankton and phytoplankton are prey items).

The physical GCM used (for details, see Yool et al., 2011) is version 3.2 of NEMO (Madec, 2008), configured at approximately $1^{\circ} \times 1^{\mathrm{o}}$ resolution, higher around the equator to improve the representation of equatorial upwelling. There are 64 levels in the vertical, increasing in thickness from approximately $6 \mathrm{~m}$ at the surface to $250 \mathrm{~m}$ at $6000 \mathrm{~m}$. In order to improve the representation of deep water circulation, partial level thicknesses are used in the specification of bottom topography. Vertical mixing is parameterised from the turbulent kinetic energy (TKE) scheme of Gaspar et al. (1990), with modifications by Madec (2008). Sea-ice is simulated using the LIM2 sea-ice submodel, coupled to the ocean every 5 ocean time steps through the non-linear quadratic drag law of the shear between sea-ice and ocean surface velocity (Timmermann et al., 2005). Temperature and salinity fields are initialised 
from a monthly climatology, with surface fields of the latter relaxed toward the climatology

464 throughout the simulation in order to prevent unacceptable drifts in salinity caused by deficiencies in freshwater forcing.

Given that the MEDUSA ecosystem model was reconfigured (above), a new spinup of the GCM was required. As for Yool et al. (2011), this spinup was a 40 year simulation, 19662005 , forced at the ocean surface with precipitation, downward short- and long-wave radiation and winds from DFS4.1 fields developed by the European DRAKKAR collaboration (DRAKKAR Group, 2007). The last 12 years of the spinup was then repeated twice, but implementing the ERSEM and HadOCC trophic transfer schemes.

\subsection{Results}

Results as presented are averages of the last four years of each of the three simulations (Fig. 7). For completeness, we also compare with biogeochemical fields predicted by MEDUSA-NEMO as published by Yool et al. (2011) in Table 2. Yool et al. (2011) concluded that their simulated patterns of nutrients and productivity were consistent with observations, including major features such as the oligotrophic gyres and plankton blooms at high latitudes. The new base run, using the reparameterised AH95 trophic transfer scheme (lower GGE), gave rise to qualitatively similar patterns of biogeochemical tracers as in Yool et al (2011).

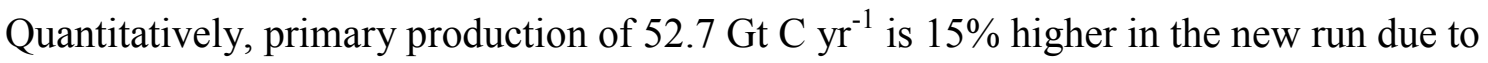
increased nutrient recycling by zooplankton but, as it happens, the Yool et al. (2011) value of 45.7 Gt $\mathrm{C} \mathrm{yr}^{-1}$ is on low end of estimates based on satellite-based chlorophyll and the new value is still lower than estimates of 58.8 and $60.4 \mathrm{Gt} \mathrm{C} \mathrm{yr}^{-1}$ by Behrenfeld and Falkowski (1997) and Carr et al. (2006) respectively. Zooplankton production as a fraction of primary production was lower than in Yool et al. (2011) because of lower GGE (the reparameterisation of AH95) and, because grazing on detritus was removed, predicted export was higher in the new simulation (Table 2). The resulting export:PP of 0.18 is the same as in 
Yool et al (2011), increasing only slightly to 0.19 and 0.20 for the simulations using the ERSEM and HadOCC trophic transfer formulations.

Predicted primary production was $\sim 10 \%$ higher in the AH95 simulation compared to that using ERSEM (Fig. 7a; Table 1), higher than the 3\% difference seen in the steady-state model (for $\theta_{P}=6.625$ ). Nutrient regeneration efficiency is the same for these two trophic transfer formulations when phytoplankton are the food source (Table 1) and so the decrease in primary production associated with ERSEM is due to the diminution in nutrient regeneration resulting from mesozooplankton grazing on microzooplankton. The most marked decreases are therefore seen in areas where mesozooplankton are most abundant including the equatorial Pacific, North Atlantic and Southern Ocean. As was seen in the steady state model, zooplankton production is closely linked to primary production and so shows decreases in the ERSEM simulation similar to that of primary production (Fig. 7c). The ZP:PP ratio remained at about 0.3 for each of the runs of the model. The predicted pattern of zooplankton biomass (Fig. 7d) is, however, more complicated. Microzooplankton account for approx. $60 \%$ of total grazing in each of the simulations and thus declining overall zooplankton biomass is largely due to the impact of primary production on this group. because they consume a mixed diet that includes microzooplankton (Table 1) which led to their biomass, and that of total zooplankton, increasing in some areas such as the Equatorial Pacific. Predicted export was 10\% lower in the ERSEM simulation due to lower primary production, representing a weakened biological pump (Fig. 7e). The HadOCC model run exhibited the lowest primary production (16\% less than for AH95, with a similar change, $51017 \%$ in the steady state model) as nutrient generation by zooplankton is only $6-13 \%$ of intake 511 (Table 1), with associated decreases in zooplankton production and stocks of phytoplankton and zooplankton (Fig. 7a-d). The most interesting result is seen in the global distribution of 
513

export predicted by the HadOCC model run. On the one hand, export decreases because of decreased primary production but, on the other, it increases in areas where diatoms are abundant because of the high allocation to fast-sinking faecal pellets (Table 1) that largely escape remineralisation in the upper water column. Overall, results show that relatively small changes in allocation of $\mathrm{N}$ intake to remineralisation or detritus (NGGE was the same in each case) gave rise to significant variation in predicted biogeochemical fields.

\section{Discussion}

When it comes to ecosystem modelling, it may be that even small changes in mathematical specification are amplified in model predictions (Wood and Thomas, 1999; Fussmann and Blasius, 2005). The implication is clear: accuracy is required in formulation and parameter values and, moreover, in the representation of the physico-chemical environment (Anderson, 2005). In a previous study focusing on zooplankton, Anderson et al. (2010) showed that the predicted distributions of plankton functional types in a biogeochemical GCM were sensitive to choice of functional response, a problem that is exacerbated by sensitivity to model physics and associated environmental forcing (Sinha et al., 2010). Here, we compared the performance of four contemporary trophic transfer formulations in two settings, a steady state food web model and a 3D biogeochemical GCM. The formulations differed in the way consumer growth was calculated as a function of food $\mathrm{C}: \mathrm{N}$ ratio and in their assumptions for the fate of the non-limiting element. Results varied markedly for predictions of primary production, transfer to higher trophic levels and export, in both the steady state and 3D models.

At the outset, we should point out that our main priority is not to try and say which of the four chosen trophic transfer formulations is in some way the best, but rather to show that their disparate assumptions lead to contrasting biogeochemical simulations. In turn, this flags the 
need for further investigation of the underlying assumptions, e.g., by comparing the different 3D simulations with global datasets for variables such as chlorophyll, primary production and nutrients, in order to see which showed the closest agreement. This is outside the scope of our work and, moreover, doing so would not have been a particularly meaningful exercise. For starters, parameter values used in the trophic transfer schemes were not tuned in any of the simulations which is arguably necessary in order to achieve an objective comparison. Without tuning, AH95 may have an unfair advantage because it was the formulation used in the MEDUSA ecosystem model as first published by Yool et al. (2011) and which forms the basis of our study. Further, even if we had undertaken parameter tuning, this is in itself problematic because the parameterisation of marine ecosystem models is often underdetermined by data (Ward at al., 2010). Errors elsewhere in the ecosystem model, such as those generated by physics, could confound conclusions drawn from a comparison of trophic transfer schemes in the 3D model.

\subsection{Ecosystem dynamics and export}

The predicted magnitude of regenerated production, and therefore primary production in total, varied between trophic transfer formulations depending on the extent to which $\mathrm{N}$ was regenerated by zooplankton excretion and so was highest for ERSEM and Pah08. Substantial errors may often occur in predicting primary production in GCMs, especially the gross underestimation seen in the oligotrophic subtropical gyres (Oschlies et al., 2000). One way to improve the match with data is to include an implicit microbial loop via a rapid recycling pathway from phytoplankton directly to inorganic nutrient (Doney et al., 1996) allowing primary production to be increased "by almost any factor desired" (Oschlies, 2001). Although such extreme variation was not the case here, predicted primary production did vary by as much as $10 \%$ in the $3 \mathrm{D}$ model depending on choice of trophic transfer scheme. 
Predicted zooplankton production (ZP) is, unsurprisingly, sensitive to N GGE and how it is parameterised. An interesting statistic, not often mentioned in modelling studies, is the ratio of zooplankton production to primary production, ZP:PP (usually expressed in C units). For $\theta_{\mathrm{P}}=6.625$, predicted ZP:PP (for $\mathrm{C}$ ) in the steady state model was 0.31 for the AH95 formulation and 0.35 for Pah03, ERSEM and HadOCC, decreasing at higher $\theta_{\mathrm{P}}$ as $\mathrm{N}$ becomes progressively limiting and C is in excess. Stock and Dunne (2010) estimated that mesozooplankton production as a fraction of primary production, the $z$-ratio, varied between 0.01 and 0.04 in unproductive systems, increasing to between 0.1 and 0.2 when primary productivity was high. Mesozooplankton such as copepods may however account for only a relatively minor fraction phytoplankton grazing losses (e.g., 23\%: Calbet, 2001). Rather, as much as 59 to $75 \%$ of primary production may instead be consumed by microzooplankton (Calbet and Landry, 2004). The z-ratio, as estimated by Stock and Dunne (2010), therefore likely significantly underestimates total ZP:PP. In this context, one can argue that these two zooplankton groups should be represented differently in models, taking into account the physiological differences between organisms that phagocytose their food and those animals with a gut (Mitra and Flynn, 2007).

Although herbivore growth was directly impacted by food quality, these zooplankton prevented variability associated with phytoplankton $\mathrm{C}: \mathrm{N}$ propagating up the food web in the model because they are assumed to be homeostatic with respect to their body composition. Theoretically, secondary consumers and higher trophic levels may thus be expected to be unaffected by the stoichiometry of primary production, except via quantitative changes to herbivore production (Brett, 1993; Boersma et al., 2009). If herbivores are predicted to be limited by N, which occurs for $\theta_{\mathrm{P}}>5.5$ when using the ERSEM, HadOCC and Pah08 trophic transfer formulations, their production is also independent of phytoplankton $\mathrm{C}: \mathrm{N}$ and the functioning of the food web depends only on N. In this case, food chain efficiency (FCE), 
587

defined as the proportion of energy fixed by primary producers that is transferred to upper trophic levels, decreases with increasing $\theta_{\mathrm{P}}$. These results highlight the importance of both the assumption of homoeostasis and the need to understand how limiting factors associated with food quality determine the growth of zooplankton (see section 5.2, below).

Export via sinking detritus also showed significant variation, depending on the choice of trophic transfer formulation. Differences were minimal at low phytoplankton C:N, e.g. the Redfield ratio of 6.625 , in the steady state model. At high $\theta_{\mathrm{P}}$, however, carbon export was as much as $50 \%$ higher when using the ERSEM and Pah08 formulations because these allocate excess $\mathrm{C}$ to faecal pellets, as compared to $\mathrm{AH} 95$ where it is instead released as $\mathrm{CO}_{2}$. The predicted export of fast sinking detritus varied less because, being produced as carnivore faecal pellets, stoichiometric variability associated with phytoplankton had been ironed out by the herbivores. Predicted export varied by an average of almost $10 \%$ between the different trophic transfer formulations in the 3D GCM, in this case for a fixed C:N in phytoplankton of 6.625. Regional variations were often greater, reflecting changes in both predicted primary production and assumptions relating to zooplankton absorption efficiency.

\subsection{Stoichiometry in focus}

Although metazoans in general have a much tighter regulation of their elemental ratios than autotrophs (Sterner and Elser 2002), the common model assumption that zooplankton have fixed elemental ratios in biomass, i.e., exhibit homeostasis, is nevertheless open to question. While many experimental studies using nutrient limited algae have demonstrated grazer deviations from homeostasis, secondary consumers may also experience such deviations, especially with regard to C:P (Dickman et al., 2008; Malzahn et al., 2010; Schoo et al., 2010). Seasonal changes in $\mathrm{C}$ and $\mathrm{N}$ content are known to occur in copepods from high latitudes due to lipid accumulation (Tande, 1982; Donnelly et al., 1994), largely reflecting ontogenetic differences in lipid sequestration and catabolism (Kattner and Krause, 1987; 
612 Kattner et al., 1994; Mayzaud et al., 2011). Indeed, it may be that at high latitude,

613 overwintering copepods should be considered as two-compartment systems in a

614 stoichiometric context, with lipids sacs (consisting mostly of wax esters) and somatic tissue

615 as separate entities.

616 Homoeostasis aside, the limitation of zooplankton production remains incompletely

617 understood. The question "carbon or nitrogen limitation of marine copepods?" was asked

618 more than 15 years ago by Anderson and Hessen (1995) yet, despite advances in

619 experimental ecology and stoichiometric theory, it remains to be comprehensively answered.

620 There is now a greater appreciation of the roles of many factors in zooplankton nutrition and

621 stoichiometric balance including the potential for limitation by fatty acids and other

622 micronutrients (Anderson and Pond, 2000; Anderson et al., 2004), nutrient element

623 requirements for maintenance (Boersma and Kreutzer, 2002; Mayor et al., 2011), the

624 potential for maternal biomass to fuel production (Mayor et al., 2009a,b) and the influence of

625 gut residence time (Thor and Wendt, 2010) and biochemical composition (Reinfelder and

626 Fisher, 1991; Anderson, 1994; Mayor et al., 2011) in determining absorption efficiencies.

627 Providing reliable equations to calculate zooplankton production on the basis of these factors

628 is an ongoing challenge for modellers. In particular, the whole concept of Liebig-style

629 limitation of zooplankton production is open to scrutiny, an alternative approach being, for

630 example, the use of Dynamic Energy Budget theory in which different reaction pathways

631 using $\mathrm{C}$ and $\mathrm{N}$ proceed on a probabilistic basis using synthesising units (Kuijper et al., 2004).

632 The various trophic transfer schemes investigated here involve different choices regarding

633 whether stoichiometric regulation occurs pre-or post-absorption by the gut, which has

634 particular biogeochemical implications for whether organic matter is recycled in inorganic

635 form in the upper ocean, or exported to depth as sinking detritus. If one consults the

636 contemporary literature on plankton physiology, there would appear to be little exact 
637 knowledge on the mechanisms of stoichiometric regulation in metazoans (Hessen and 638 Anderson, 2008). Anderson et al. (2005) proposed that, although digestive plasticity allows 639 some flexibility for consumers to regulate stoichiometric balance in response to shifts in diet 640 quality, especially long term variations, generalist consumers should employ post-absorptive 641 regulation as an effective means of dealing with short term variations in food quality. In 642 theory, this allows animals to effectively monitor available substrates, in the same way that 643 hormonal systems operate in higher animals. Experimental studies have provided evidence of 644 disposal of excess $\mathrm{C}$ as dissolved organic material (Darchambeau et al., 2003) or as respiration to $\mathrm{CO}_{2}$ (Jensen et al., 2006; Jensen and Hessen, 2007). Yet, others have provided evidence for defecation of C-rich compounds by zooplankton via enzymatic discrimination in the gut (DeMott et al., 1998) which may be a useful strategy if food items follow predictable, e.g. seasonal, changes in food quality. Matters are complicated further by the interaction between food quality and quantity, the effects of which are often mutually at odds with each other, with important trophic implications (Mitra and Flynn, 2007; Flynn, 2009).

\subsection{Adequacy of existing parameterisations}

What are we to conclude about the suitability of the different trophic transfer schemes investigated herein for use in marine ecosystem models? Any or all of them can be readily criticised with regard to their underlying assumptions. None take into account the effect of food quantity on absorption efficiency, nor biochemical aspects of nutrition (although the originally published version of AH95 did separate $\mathrm{C}$ between protein and lipids/carbohydrates and specify separate AEs for each). The ERSEM, HadOCC and Pah08 formulations each make the apparently simplistic assumption that the ideal food $\mathrm{C}: \mathrm{N}$ equals that of consumer biomass, arguably without a full appreciation of metabolic requirements

660 (although it should be noted that, as parameterised, they do a reasonable job at reproducing 661 the data set of Kiørboe (1989) shown in Fig. 3). It is also possible to question the efficacy of 
662

663

664

665

666

667

668

669

670

671

672

673

674

675

676

677

678

679

680

681

682

683

684

685

686

calculating growth Liebig-style based on empirical gross growth efficiency parameters.

Regarding the fate of non-limiting substrates, there was no consensus as to whether stoichiometric regulation of $\mathrm{C}$ and $\mathrm{N}$ in excess should be pre-or post-absorption by the gut, an important decision because it impacts on predicted nutrient recycling and export. Matters are not improved by the fact that, in the published originals, little or no justification is generally provided for the various assumptions that were made.

The fact that the assumptions in the four trophic transfer schemes were so disparate suggests a lack of consensus within the scientific community as to how trophic transfer is to be modelled. The implication is that more information is needed on the nutritional factors controlling growth efficiency in consumers, stoichiometric regulation of homoeostasis (e.g., pre-versus post-absorptive), the fate of substrates in stoichiometric excess, absorption efficiency, and the metabolic budgets of zooplankton, especially the factors contributing to maintenance. Improved estimates of processes such as protein turnover, and other metabolic costs, are required (Mayor et al., 2011).

On the other hand, it is easy for modellers to deflect attention from model deficiencies by pointing to insufficient information or understanding on key processes or organisms.

Scientists live today in a hustle bustle, publish or perish society. Everyone is pressed for time and ignorance (e.g. because of lack of time to familiarise with the latest literature) and indifference (lack of interest) are easy traps for modellers, as well as other scientists, to fall into (Anderson and Mitra, 2010). As the English poet Thomas Gray said, "Where ignorance is bliss, ,tis folly to be wise” (i.e., what you do not know cannot hurt you). In moderation, we should note that it is nigh impossible to keep on top of the ever-growing mountain of literature that confronts scientists today. This is especially so if numerous disciplines are to be covered, as is often the case for modellers, highlighting the need to initiate and/or maintain genuine, active dialogue between the modelling and observational/experimental communities 
687 (Flynn, 2005). Another problem is inertia since, once a model is operational and published,

688

689

690

691

692

693

694

695

696

697

698

699

700

701

702

703

704

705

706

707

708

709

710

711 modellers often remain faithful to that version regardless of changes to our understanding. Revisiting equations is potentially awkward since it changes the model from its original, citable form and may also require a retuning exercise which can, as when using GCMs, be prohibitively costly in time and effort. It is thus easy to see how multiple factors conspire to allow outdated formulations to be retained in ecosystem models. Our aim here is to raise awareness of these potential pitfalls.

Advanced parameterisations of trophic transfer, beyond the formulations investigated here, have been developed in recent years, although have not as yet been implemented within GCMs. Anderson et al (2005) developed a model of trophic transfer which did away with the empirical gross growth efficiency parameters, replacing them with a detailed description of the costs of maintenance and growth, with C-rich substrates preferentially utilised thereby sparing $\mathrm{N}$ in proteins for growth. Mitra (2006) also developed an advanced parameterisation where respiration included separate terms for basal metabolism (maintenance of osmotic and ionic gradients, enzyme turnover and DNA repair) and metabolism (including synthesis of new biomass). Zooplankton growth is calculated as ingestion minus respiration and voiding to faeces, with excess substrates incorporated primarily into the latter. We chose not to include these transfer schemes in the analysis presented here because they represent basal metabolic costs of consumers in a completely different way, preventing a consistent approach for the comparison (see section 2). If metabolic costs are equalised, the Anderson et al. (2005) trophic transfer scheme exactly reduces to AH95. Our comparison of trophic transfer schemes focused on assumptions relating to the calculation of growth and on the fate of nonlimiting substrates. A further point for consideration by modellers is the specification of energetic costs associated with basal metabolism and growth. In aspects other than the explicit calculation of maintenance and bioenergetic costs, for which parameter values such 
as protein turnover are often hard to come by (Mayor et al., 2011), the Anderson et al. (2005) and Mitra (2006) formulations are remarkably similar to AH95, ERSEM, HadOCC and Pah08 in that they make simple assumptions for Liebig-style limitation of production and as to whether excess $\mathrm{C}$ and $\mathrm{N}$ is respired/excreted post-absorption by the gut. For organisms with a gut, there is an important linkage between absorption of food and gut transit time (Paffenhöfer and Van Sant, 1985; Tirelli and Mayzaud, 2005). By including this, the model of Mitra and Flynn (2007) represents a significant departure from other formulations of trophic transfer which has the potential to significantly change the dynamics of the whole system through a process of density dependent inefficiency (Mitra and Flynn 2007; Flynn, 2009). The extra complexity associated with these trophic transfer schemes brings problems with assigning suitable parameter values, a common issue with increasing complexity in models. They should be used to help in the formulation of simpler model structures that are amenable for placement in ecosystem models.

\subsection{Concluding remarks}

Worrying inconsistencies are evident in the way in which fundamental transfer processes are justified and parameterised in the current generation of marine ecosystem models. Our results using a simple steady state model and a 3D GCM showed that this lack of conformity manifested itself in the simulation of ocean biogeochemistry, notably primary production, transfer to higher trophic levels and export. As a result, "one wonders ... to what extent the parameterisations used in the current generation of complex ecosystem models being developed for climate studies, and the predictions thereof, can be relied upon" (Anderson and Mitra, 2010). Identifying the most appropriate formulations for use in ecosystem models is, however, no easy matter. We made no attempt to do so on the basis of comparing our 3D simulations to see which agreed most closely with data, because of the problem of underdetermination (Ward et al., 2010). This does not mean, however, that the 
737 parameterisation of ecosystem models, including those for use in global GCMs, is a forlorn

738 task. Parameter tuning and investigation can instead be undertaken for local, data-rich

739 domains such as the various time series stations that adorn the world oceans. Equally

740 important is for modellers to ensure that the component parts of their models are parameterised individually to the highest standards on the basis of known physiology. Local inadequacies in the equations and parameterisation need to be identified and related to underlying assumptions. Only then can "piecemeal engineering" (Simon, 1996) be carried out to modify the offending parts.

Overall, our work has highlighted serious deficiencies in the way in which trophic transfer is parameterised in contemporary marine ecosystem models. It demonstrates the need for modellers to adopt a back to basics approach and revisit some of the basic assumptions used in the formulation of zooplankton, involving active dialogue between modellers and the observational/experimental community. It will of course also require consideration of the usual trade-off between simplicity for the sake of pragmatic parameterisation, and complexity to achieve the desired basis in reality. If the underlying physiology in models is not afforded due attention, then it may be that our models are like "castles built on sand" (Flynn, 2005).

Acknowledgements

TRA and AXY are funded by the Natural Environment Research Council, U.K, as is DJM (NE/G014744/1). The work was part funded by the European Union Seventh Framework Programme EURO-BASIN ([FP7/2007-2013] [ENV.2010.2.2.1-1 ENV.2010.2.2.1-1 ENV.; grant agreement $\left.n^{\circ} 264933\right]$. 
762

763

764

765

766

767

768

769

770

771

772

773

774

775

776

777

778

779

780

781

782

783

784

785

\section{References}

Acheampong, E., Nielen, M.H., Mitra, A., St. John, M.A., 2012. Towards an adaptive model for simulating growth of marine mesozooplankton: A macromolecular perspective. Ecol. Modell. 225, 1-18.

Andersen, T., Hessen, D.O., 1991. Carbon, nitrogen and phosphorus content of freshwater zooplankton. Limnol. Oceanogr. 36, 807-814.

Anderson, T.R., 1992. Modelling the influence of food C:N ratio, and respiration on the growth and nitrogen excretion in marine zooplankton and bacteria. J. Plankton Res. 14, $1645-1671$.

Anderson, T.R., 1994. Relating C:N ratios in zooplankton food and faecal pellets using a biochemical model. J. Exp. Mar. Biol. Ecol. 184, 183-199.

Anderson, T.R., 2005. Plankton functional type modelling: running before we can walk? J. Plankton Res. 27, 1073-1081.

Anderson, T.R., Hessen, D.O., 1995. Carbon or nitrogen limitation in marine copepods? J. Plankton Res. 17, 317-331.

Anderson T.R., Pond, D.W., 2000. Stoichiometric theory extended to micronutrients: comparison of the roles of essential fatty acids, carbon, and nitrogen in the nutrition of marine copepods. Limnol. Oceanogr. 45, 1162-1167.

Anderson, T.R., Pondaven, P., 2003. Non-Redfield carbon and nitrogen cycling in the Sargasso Sea: pelagic imbalances and export flux. Deep-Sea Res. Part I 50, 573-591.

Anderson, T.R., Boersma, M., Raubenheimer, D., 2004. Stoichiometry: linking elements to biochemicals. Ecology 85, 1193-1202.

Anderson, T.R., Hessen, D.O., Elser, J.J., Urabe, J., 2005. Metabolic stoichiometry and the fate of excess carbon and nutrients in consumers. Amer. Nat. 165, 1-15. 
786

787

788

789

790

791

792

793

794

795

796

797

798

799

800

801

802

803

804

805

806

807

808

809

Anderson, T.R., Mitra, A., 2010. Dysfunctionality in ecosystem models: An underrated pitfall? Prog. Oceanogr. 84, 66-68.

Anderson, T.R., Gentleman, W.C., Sinha, B., 2010. Influence of grazing formulations on the emergent properties of a complex ecosystem model in a global general circulation model. Prog. Oceanogr. 87, 201-213.

Armstrong, R.A., Lee, C., Hedges, J.I., Honjo, S., Wakeham, S.G., 2002. A new, mechanistic model for organic carbon fluxes in the ocean: based on the quantitative association of POC with ballast minerals, Deep-Sea Res. Part II 49, 219-236.

Augustin, C.B., Boersma, M., 2006. Effects of nitrogen stressed algae on different Acartia species. J. Plankton Res. 28, 429-436.

Banse, K., 1994. Grazing and zooplankton production as key controls of phytoplankton production in the open ocean. Oceanography 7, 13-20.

Beaugrand, G., Kirby, R.R., 2010. Climate, plankton and cod. Global Change Biol. 16, 12681280.

Beaugrand, G., Edwards, M., Legendre, L., 2010. Marine biodiversity, ecosystem functioning, and carbon cycles. Proc. Natl. Acad. Sci., USA 107, 10120-10124.

Behrenfeld, M.J., Falkowski, P.G., 1997. Photosynthetic rates derived from satellite-based chlorophyll concentration. Limnol. Oceanogr. 42, 1-20.

Blackford, J.C., Allen, J.I., Gilbert, F.J., 2004. Ecosystem dynamics at six contrasting sites: a generic modelling study. J. Mar. Syst. 52, 191-215.

Boersma, M., Kreutzer C., 2002. Life at the edge: Is food quality really of minor importance at low quantities? Ecology 83, 2552-2561.

Boersma, M., Becker, C., Malzahn, A.M., Vernooij, R., 2009. Food chain effects of nutrient limitation in primary producers. Mar. Freshw. Res. 60, 983-989. 
810

811

812

Bratbak, G., Heldal, M., Thingstad, T.F., Tuomi, P., 1996. Dynamics of virus abundance in coastal seawater. FEMS Microbiol. Ecol. 19, 263-269.

Brett, M.T., 1993. Comment on "Possibility of N or P limitation for planktonic cladocerans: An experimental test" (Urabe and Watanabe) and "Nutrient element limitation of zooplankton production” (Hessen). Limnol. Oceanogr. 38, 1333-1337.

Burns, C.W., Brett, M.T., Schallenberg, M., 2011. A comparison of the trophic transfer of fatty acids in freshwater plankton by cladocerans and calanoid copepods. Freshwater Biol. $56,889-903$.

Calbet, A., 2001. Mesozooplankton grazing effect on primary production: A global comparative analysis in marine ecosystems. Limnol. Oceanogr. 46, 1824-1830.

Calbet, A., Landry, M.R., 2004. Phytoplankton growth, microzooplankton grazing, and carbon cycling in marine systems. Limnol. Oceanogr. 49, 51-57.

Carlotti, F., Poggiale, J.C., 2010. Towards methodological approaches to implement the zooplankton component in ,,end to end” food-web models. Prog. Oceanogr. 84, 20-38.

Carr, M.-E., Friedrichs, M.A.M., Schmeltz, M. et al., 2006. A comparison of global estimates of marine primary production from ocean color, Deep-Sea Res. Part II 53, 741-770.

Checkley, D.M. Jr., 1980. The egg production of a marine planktic copepod in relation to its food supply: Laboratory studies. Limnol. Oceanogr. 25, 430-446.

Chen, C.-T.A., Lin, C.-M., Huang, B.-T., Chang, L.-F., 1996. Stoichiometry of carbon, hydrogen, nitrogen, sulfur and oxygen in the particulate matter of the western North Pacific marginal seas. Mar. Chem. 54, 179-190.

Daly, K.L., Wallace, D.W.R., Smith, W.O.Jr., Skoog, A., Lara, R., Gosselin, M., Falck, E., Yager, P.L., 1999. Non-Redfield carbon and nitrogen cycling in the Arctic: Effects of ecosystem structure and dynamics. J. Geophys. Res. 104, 3185-3199. 
834 Darchambeau, F., Faerøvig, P.J., Hessen, D.O., 2003. How Daphnia copes with excess

835 carbon in its food. Oecologia (Berlin) 136, 336-346.

836 DeMott, W.R., Gulati, R.D., Siewertsen, K., 1998. Effects of phosphorus-deficient diets on

837 the carbon and phosphorus balance of Daphnia magna. Limnol. Oceanogr. 43, 1147-1161.

838 Dickman, E.M., Vanni, M.J., Horgan, M.J., 2006. Interactive effects of light and nutrients on 839 phytoplankton stoichiometry. Oecologia 149, 676-689.

840 Dickman, E.M., Newell, J.M., González, M.J., Vanni, M.J., 2008. Light, nutrients, and food841 chain length constrain planktonic energy transfer efficiency across multiple trophic levels. 842 Proc. Natl. Acad. Sci. 105, 18408-18412.

843 Doney, S. C., Glover, D.M., Najjar, R.G., 1996. A new coupled, one-dimensional biological844 physical model for the upper ocean: Application to the JGOFS Bermuda Atlantic Time845 series Study (BATS) site. Deep-Sea Res. Part II 43, 591-624.

846 Donnelly, J., Torres, J.J., Hopkins, T.L., Lancreaft, T.M., 1994. Chemical composition of 847 Antarctic zooplankton during austral fall and winter. Polar Biol. 14, 171-183.

848 DRAKKAR Group, 2007. Eddy-permitting ocean circulation hindcasts of past decades. 849 CLIVAR Exchanges No. 42(12), 8-10.

850 Dunne, J.P., Armstrong, R.A., Gnanadesikan, A., Sarmiento, J.L., 2005. Empirical and 851 mechanistic models for the particle export ratio. Global Biogeochem. Cycles 19, GB4026, 852 doi:10.1029/2004GB002390.

853 Elser, J.J., Hassett, R.P., 1994. A stoichiometric analysis of the zooplankton-phytoplankton 854 interactions in marine and freshwater ecosystems. Nature 370, 211-213.

855 Eppley, R.W., Peterson, B.J., 1979. Particulate organic matter flux and planktonic new 856 production in the deep ocean, Nature 282, 677-680. 
857 Finkel, Z.V., Beardall, J., Flynn, K.J., Quigg, A., Rees, T.A.V., Raven, J.A., 2010.

858 Phytoplankton in a changing world: cell size and elemental stoichiometry. J. Plankton Res. $32,119-137$.

860

861

862

863

864

865

866

867

868

869

870

871

872

873

874

875

876

877

878

879

880

881

Flynn, K.J., 2005. Castles built on sand: dysfunctionality in plankton models and the inadequacy of dialogue between biologists and modellers. J. Plankton Res. 27, 1205-1210.

Flynn, K.J., 2009. Food-density dependent inefficiency in animals with a gut as a stabilising mechanism in trophic dynamics. Proc. Roy. Soc. Lond. B. 276, 1147-1152.

Flynn, K.J., 2010. Ecological modelling in a sea of variable stoichiometry; dysfunctionality and the legacy of Redfield and Monod. Prog. Oceanogr. 84, 52-65.

Frigstad, H., Andersen, T., Hessen, D.O., Naustvoll, L.-J., Johnsen, T.M., Bellerby, R.G.J., 2011. Seasonal variation in marine C:N:P stoichiometry: can the composition of seston explain stable Redfield ratios? Biogeosciences 8, 2917-2933.

Fu, F.-X., Warner, M. E., Zhang, Y. et al., 2007. Effects of increased temperature and $\mathrm{CO}_{2}$ on photosynthesis, growth, and elemental ratios in marine Synechococcus and Prochlorococcus (Cyanobacteria). J. Phycol. 43, 485-496.

Fussmann, G.F., Blasius, B., 2005. Community response to enrichment is highly sensitive to model structure. Biol. Lett. 1, 9-12.

Gaspar, P., Gregoris, Y., Lefevre, J.-M., 1990. A simple eddy kinetic energy model for simulations of the oceanic vertical mixing: Tests at station Papa and long-term upper ocean study site. J. Geophys. Res. 95, 16179-16193.

Geider, R. J., La Roche, J., 2002. Redfield revisited: variability of C:N:P in marine microalgae and its biochemical basis. Eur. J. Phycol. 37, 1-17.

Gentleman, W., Leising, A., Frost, B., Strom, S., Murray, J., 2003. Functional responses for zooplankton feeding on multiple resources: a review of assumptions and biological dynamics. Deep-Sea Research Part II 50, 2847-2875. 
882

883

884

Gismervik, I., 1997. Stoichiometry of some marine planktonic crustaceans. J. Plankton Res. $19,279-285$

González, H.E., Daneri, G., Iriarte, J.L., Yannicelli, B., Menschel, E., Barria, C., Pantoja, S., Lizzáraga, L., 2009. Carbon fluxes within the epipelagic zone of the Humboldt Current system of Chile: The significance of euphausiids and diatoms as key functional groups for the biological pump. Prog. Oceanogr. 83, 217-227.

Hassett.R.P., Landry,M.R., 1988. Short-term changes in feeding and digestion by the copepod Calanus pacificus. Mar. Biol. 99, 63-74.

Hessen, D.O., 1992. Nutrient element limitation of zooplankton production. Amer. Nat. 140, 799-814.

Hessen, D.O., Ågren, G.I., Anderson, T.R., Elser, J.J., De Ruiter P., 2004. Carbon sequestration in ecosystems: the role of stoichiometry. Ecology 85, 1179-1192.

Hessen, D.O., Anderson, T.R., 2008. Excess carbon in aquatic organisms and ecosystems: Physiological, ecological, and evolutionary implications. Limnol. Oceanogr. 53, 16851696.

Hessen, D.O., Leu, E., Færøvig, P.J., Petersen, S.F., 2008. Light and spectral properties as determinants of C:N:P-ratios in phytoplankton. Deep-Sea Res. II 55, 2169-2175.

Honjo, S., Roman, M.R., 1978. Marine copepod fecal pellets: Production, preservation and sedimentation. J. Mar. Res. 36, 45-57.

Jensen, T.C., Anderson, T.R., Daufresne, M., Hessen, D.O., 2006. Does excess carbon affect respiration of the rotifer Brachionus calyciflorus Pallas? Freshw. Biol. 51, 2320-2333.

Jensen, T.C., Hessen, D.O., 2007. Does excess dietary carbon affect respiration in Daphnia? Oecologia 152, 191-200.

Jones, R.H., Flynn, K.J., Anderson, T.R., 2002. The effect of food quality on growth efficiency in Acartia tonsa. Mar. Ecol. Prog. Ser. 235, 147-156. 
907

908

909

910

911

912

913

914

915

916

917

918

919

920

921

922

923

924

925

926

927

928

929

930

931

Juul-Pedersen, T., Michel, C., Gosselin, M., 2010. Sinking export of particular to organic material from the euphotic zone in the eastern Beaufort Sea. Mar. Ecol. Prog. Ser. 410, 5570.

Kattner, G., Krause, M., 1987. Changes in lipids during the development of Calanus finmarchicus from copepodid I to adult. Mar. Biol. 96, 511-518.

Kattner, G., Graeve, M., Hagen, W., 1994. Ontogenetic and seasonal changes in lipid and fatty acid/alcohol compositions of the sominant Antarctic copepods Calanus propinquus, Calanoides acutus and Rhincalanus gigas. Mar. Biol. 118, 367-644.

Kiørboe, T., 1989. Phytoplankton growth rate and nitrogen content: implications for feeding and fecundity in a herbivorous copepod. Mar. Ecol. Prog. Ser. 55, 229-234.

Kuijper, L.D.J., Anderson, T.R., Kooijman, S.A.L.M., 2004. C and N gross growth efficiencies of copepod egg production studied using a Dynamic Energy Budget model. J. Plankton Res. 26, 213-226.

Lampitt, R.S., Wishner,K.F., Turley,C.M., Angel,M.V., 1993. Marine snow studies in the Northeast Atlantic Ocean: distribution, composition and role as a food source for migrating plankton. Mar. Biol. 116, 689-702.

Leonard, C.L., McLain, C.R., Murtugudde, R., Hofmann, E.E., Harding, L.W. Jr., 1999. An iron-based ecosystem model of the central equatorial Pacific. J. Ggophys. Res. 104, 1325 1341.

Madec, G., 2008. NEMO reference manual, ocean dynamic component: NEMO-OPA, Note du Pole de mod'elisation, Institut Pierre Simon Laplace, Technical Report 27, Note du Pole de mod'elisation, Institut Pierre Simmon Laplace, France, No. 27.

Malzahn, A.M., Hantzsche, F., Schoo, K.L., Boersma, M., Aberle, N., 2010. Differential effects of nutrient-limited primary production on primary, secondary or tertiary consumers. Oecologia 162, 35-48. 
932

933

934

935

936

937

938

939

940

941

942

943

944

945

946

947

948

949

950

951

952

953

954

Mayor, D.J., Anderson, T.R., Pond, D.W., Irigoien, X., 2009a. Egg production and associated losses of carbon, nitrogen and fatty acids from maternal biomass in Calnus finmarchicus before the spring bloom. J. Mar. Syst. 78, 505-510.

Mayor, D.J., Anderson, T.R., Pond, D.W., Irigoien, X., 2009b. Limitation of egg production of Calanus finmarchicus in the field: A stoichiometric analysis. J. Mar. Syst. 78, 511-517.

Mayor, D.J., Cook, K., Thornton, B., Walsham, P., Witte, U.F.M., Zuur, A.F., Anderson, T.R., 2011. Absorption efficiencies and basal turnover of $\mathrm{C}, \mathrm{N}$ and fatty acids in a marine Calanoid copepod. Funct. Ecol. 25, 509-518.

Mayzaud, P., Lacombre, S., Boutoute, M., 2011. Seasonal and growth stage changes in lipid and fatty acid composition in the multigeneration copepod Drepanopus pectinatus from Iles Kerguelen. Antarct. Sci. 23, 3-17.

Michaels, A.F., Silver, M.W., 1988. Primary Production, sinking fluxes and the microbial food web. Deep-Sea Research 35, 473-490.

Mitra, A., 2006. A multi-nutrient model for the description of stoichiometric modulation of predation in micro- and mesozooplankton. J. Plankton Res. 28, 597-611.

Mitra, A., Flynn, K.J., 2005. Predator-prey interactions: is "ecological stoichiometry" sufficient when good food goes bad? J. Plankton Res. 27, 393-399.

Mitra, A., Flynn, K.J., 2006. Accounting for variation in prey selectivity by zooplankton. Ecol. Model. 199, 82-92.

Mitra, A., Flynn, K.J., 2007. Effects of food quality and quantity on consumer gut passage time; impacts on predation kinetics and trophic dynamics. Am. Nat. 169, 632-646.

Oschlies, A., 2001. Model-derived estimates of new production: New results point towards lower values. Deep-Sea Res. Part II 48, 2173-2197. 
Oschlies, A., Koeve, W., Garçon, V., 2000. An eddy-permitting coupled physical-biological model of the North Atlantic. Part II: Ecosystem dynamics and comparison with satellite and JGOFS local studies data. Global Biogeochem. Cycles 14, 499-523.

Paffenhöfer, G. A., Van Sant, K.B., 1985. The feeding response of a marine planktonic copepod to quantity and quality of particles. Mar. Ecol. Prog. Ser. 27, 55-65.

Pahlow, M., Vézina, A.F., Casault, B., Maass, H., Malloch, L., Wright, D.G., Lu, Y., 2008. Adaptive model of plankton dynamics for the North Atlantic. Prog. Oceanogr. 76, 151191.

Palmer, J.R., Totterdell, I.J., 2001. Production and export in a global ocean ecosystem model. Deep-Sea Res. Part I 48, 1169-1198.

Penry, D., 1998. Applications of efficiency measurements in bioaccumulation studies: definitions, clarifications, and a critique of methods. Environ. Toxicol. Chem. 17, 16331639.

Reinfelder, J.R., Fisher, N.S., 1991. The assimilation of elements ingested by marine copepods. Science 251, 794-796.

Salihoglu, B., Garçon, V., Oschlies, A., Lomas, M.W., 2008. Influence of nutrient utilization and remineralization stoichiometry on phytoplankton species and carbon export: A modeling study at BATS. Deep-Sea Res. Part I 55, 73-107.

Sarmiento, J.L., Slater, R.D., Fasham, M.J.F., Ducklow, H.W., Toggweiler, J.R., Evans, G.T., 1993. A seasonal three-dimensional ecosystem model of nitrogen cycling in the North Atlantic euphotic zone. Global Biogeochem. Cycles 7, 417-450.

Schmittner, A., Oschlies, A., Giraud, X., Eby, M., Simmons, H.L., 2005. A global model of the marine ecosystem for long-term simulations: Sensitivity to ocean mixing, buoyancy forcing, particle sinking, and dissolved organic matter cycling. Global Biogeochem. Cycles 19, GB3004, doi:10.1029/2004GB002283. 
980

981

982

983

984

985

986

987

988

989

990

991

992

993

994

995

996

997

998

999

1000

1001

1002

1003

1004

Schoo, K.L., Aberle, N., Malzahn, A.M., Boersma, M., 2010. Does the nutrient stoichiomatry of primary producers affect the secondary consumer Pleurobrachia pileus? Aquat. Ecol. 44, 233-242.

Simon, H.A., 1996. The Sciences of the Artificial, 3rd ed. MIT Press, Cambridge,

Massachusetts. $231 \mathrm{pp}$.

Sinha, B., Buitenhuis, E.T., Le Quéré, C., Anderson, T.R., 2010. Comparison of the emergent behavior of a complex ecosystem model in two ocean general circulation models. Prog. Oceanogr. 84, 204-224.

Six, K. D., Maier-Reimer, E., 1996. Effects of plankton dynamics on seasonal carbon fluxes in an ocean general circulation model, Global Biogeochem. Cycles 10, 559-583.

Siuda, A.N.S., Dam, H.G., 2010. Effects of omnivory and predator-prey elemental stoichiometry on planktonic trophic interactions. Limnol. Oceanogr. 55, 2107-2116.

Slagstad, D., Wassmann, P., 2001. Modelling the 3-D carbon flux across the Iberian Margin during the upwelling season in 1998. Prog. Oceanogr. 51, 467-497.

Sterner R.W., Elser J.J., 2002. Ecological stoichiometry: the biology of elements from molecules to the biosphere. Princeton University Press, Princeton, 439 pp.

Sterner, R.W., Andersen, T., Elser, J.J., Hessen, D.O., Hood, J.M., McCauley, E., Urabe, J., 2008. Scale-dependent carbon:nitrogen:phosphorus seston stoichiometry in marine and freshwaters. Limnol. Oceanogr. 53, 1169-1180.

Stock, C., Dunne, D., 2010. Controls on the ratio of mesozooplankton production to primary production in marine ecosystems. Deep Sea Res. Part I 57, 95-112.

Tande, K.S., 1982. Ecological investigations on the zooplankton community of Balsfjorden, northern Norway - generation cycles, and variations in body weight and body content of carbon and nitrogen related to overwintering and reproduction in the copepod Calanus finmarchicus (Gunnerus). J. Exp. Mar. Biol. Ecol. 62, 129-142. 
1005

1006

1007

1008

1009

1010

1011

1012

1013

1014

1015

1016

1017

1018

1019

1020

1021

1022

1023

1024

1025

1026

1027

Thingstad, T.F., 2000. Elements of a theory for the mechanisms controlling abundance, diversity, and biogeochemical role of lytic bacterial viruses in aquatic systems. Limnol. Oceanogr. 45, 1320-1328.

Thor, P., Wendt, I., 2010. Functional response of carbon absorption efficiency in the pelagic calanoid copepod Acartia tonsa. Limnol. Oceanogr. 55, 1779-1789.

Timmermann, R., Goosse, H., Madec, G., Fichefet, T., Ethe, C. and Duliere, V., 2005. On the representation of high latitude processes in the ORCA-LIM global coupled sea ice-ocean model. Ocean Model. 8, 175-201.

Tirelli, V., Mayzaud, P., 2005. Relationship between functional response and gut transit time in the calanoid copepod Acartia clausi: role of food quantity and quality. J. Plankton Res. $27,557-568$

Turner, J.T., 2002. Zooplankton fecal pellets, marine snow and sinking phytoplankton blooms. Aquat. Microb. Ecol. 27, 57-102.

Ward, B.A., Friedrichs, M.A.M., Anderson, T.R., Oschlies, A., 2010. Parameter optimisation techniques and the problem of underdetermination in marine biogeochemical models. $\mathrm{J}$. Mar. Syst. 81, 34-43.

Wood, S.N., Thomas, M.B., 1999. Super-sensitivity to structure in biological models. Proc. R. Soc. Lond. B 266, 565-570.

Yamanaka, Y., Tajika, E., 1997. Role of dissolved organic matter in the marine biogeochemical cycle: Studies using an ocean biogeochemical general circulation model. Global Biogeochem. Cycles 11, 599-612.

Yool, A., Popova, E.E., Anderson, T.R., 2011. MEDUSA-1.0: a new intermediate complexity plankton ecosystem model for the global domain. Geosci. Model Dev. 4, 381-417. 
1029

1030

1031

1032

1033

1034

1035

1036

1037

1038

1039

1040

1041

1042

1043

1044

1045

1046

1047

1048

1049

1050

1051

1052

\section{Figure Legends}

Figure 1. Flow pathways of the 4 trophic transfer schemes. Ingested food (I) is allocated to zooplankton biomass (Z), faecal material (detritus: D), dissolved organic matter (DOM), $\mathrm{CO}_{2}$ and inorganic $\mathrm{N}\left(\mathrm{NH}_{4}\right)$. C flows unshaded, $\mathrm{N}$ flows shaded. Release of substrates in stoichiometric excess is shown in hexagons.

Figure 2. Comparison of allocation schemes for the AH95, ERSEM, HadOCC and Pah08 trophic transfer formulations: predicted allocation of a) $\mathrm{N}$ and b) $\mathrm{C}$ in ingested food between growth (black), faecal pellets (grey) and excretion/respiration (stippled), for food C:N varying between 4 and 20 .

Figure 3. Comparison of predicted gross growth efficiencies for a) $\mathrm{N}$ and b) $\mathrm{C}$ using the AH95 and ERSEM trophic transfer formulations with the experimental data for the copepod Acartia tonsa feeding on the diatom Thalassiosira weissflogii (Kiørboe, 1989).

Figure 4. Flow diagram of the steady state model showing how new (Pn) and regenerated (Pr) production by phytoplankton $(\mathrm{P})$, consuming nitrate $(\mathrm{N})$ and ammonium $(\mathrm{A})$ respectively, is cycled via herbivores $(\mathrm{H})$ and an infinite chain of carnivores $(\mathrm{Z})$, leading to export (Ex) via slow- and fast-sinking detritus $\left(\mathrm{D}_{1}\right.$ and $\left.\mathrm{D}_{2}\right)$.

Figure 5. Solutions of the steady state model, for $\theta_{\mathrm{P}}$ between 4 and 20 , in each case to normalised to $P_{n}$ : a) primary production $\left(P_{n}+P_{r}\right)$, b) herbivore production $\left.\left(G_{H}\right), c\right)$ carnivore production $\left.\left(\mathrm{G}_{\mathrm{Z}}\right), \mathrm{d}\right) \mathrm{C}$ export via fraction $\mathrm{D}_{1}\left(\operatorname{Ex}_{\mathrm{D} 1(\mathrm{C})}\right)$, e) C export via fraction $\mathrm{D}_{2}\left(\operatorname{Ex}_{\mathrm{D} 2(\mathrm{C})}\right)$, f) $\mathrm{C}: \mathrm{N}$ of export (given that $\mathrm{P}_{\mathrm{n}}=1$, this equals total export, $\mathrm{Ex}_{\mathrm{D} 1(\mathrm{C})}+\mathrm{Ex}_{\mathrm{D} 2(\mathrm{C})}$ ).

Figure 6. Flow diagram of the MEDUSA ecosystem model (Yool et al., 2011).

Figure 7. Comparison of simulated biogeochemical fields in MEDUSA-NEMO for the different trophic transfer formulations. Predicted values shown for AH95 and the absolute difference from AH95 for ERSEM/Pah08 and HadOCC. 
Table 1. Nitrogen allocation fractions for each of the four trophic transfer schemes, for $\theta_{\mathrm{f}}=$ 5.5, 6.625.

\begin{tabular}{|c|c|c|c|c|}
\hline Formulation & $\theta_{\mathrm{f}}$ & growth & excretion & pellets \\
\hline AH95 & 5.5 & 0.42 & 0.28 & 0.3 \\
\hline ERSEM & 5.5 & 0.5 & 0.2 & 0.3 \\
\hline Pah08 & 5.5 & 0.5 & 0.2 & 0.3 \\
\hline HadOCC & 5.5 & 0.5 & 0.13 & 0.37 \\
\hline AH95 & 6.625 & 0.5 & 0.2 & 0.3 \\
\hline ERSEM & 6.625 & 0.5 & 0.2 & 0.3 \\
\hline Pah08 & 6.625 & 0.5 & 0.2 & 0.3 \\
\hline HadOCC & 6.625 & 0.5 & 0.06 & 0.44 \\
\hline
\end{tabular}


Table 2. Summary statistics for average fluxes and concentrations of tracers, last 4 years of simulation, compared with results from Yool et al. (2011).

\begin{tabular}{|c|c|c|c|}
\hline Yool et al., 2011 & $\underline{\mathrm{AH} 95}$ & $\underline{\text { ERSEM/Pah08 }}$ & $\underline{\text { HadOCC }}$ \\
\hline 6.01 & 6.01 & 5.99 & 5.82 \\
\hline 0.37 & 0.39 & 0.38 & 0.36 \\
\hline 4.38 & 5.05 & 4.48 & 4.26 \\
\hline 0.30 & 0.26 & 0.26 & 0.24 \\
\hline 1.94 & 1.50 & 1.38 & 1.25 \\
\hline 0.44 & 0.30 & 0.31 & 0.29 \\
\hline 0.30 & 0.52 & 0.47 & 0.53 \\
\hline 0.51 & 0.40 & 0.37 & 0.34 \\
\hline 0.81 & 0.92 & 0.84 & 0.87 \\
\hline 0.18 & 0.18 & 0.19 & 0.20 \\
\hline
\end{tabular}

Units $-1: \mathrm{mmol} \mathrm{N} \mathrm{m}^{-3} ; 2: \mathrm{mmol} \mathrm{N} \mathrm{m}^{-2} \mathrm{~d}^{-1}$ 


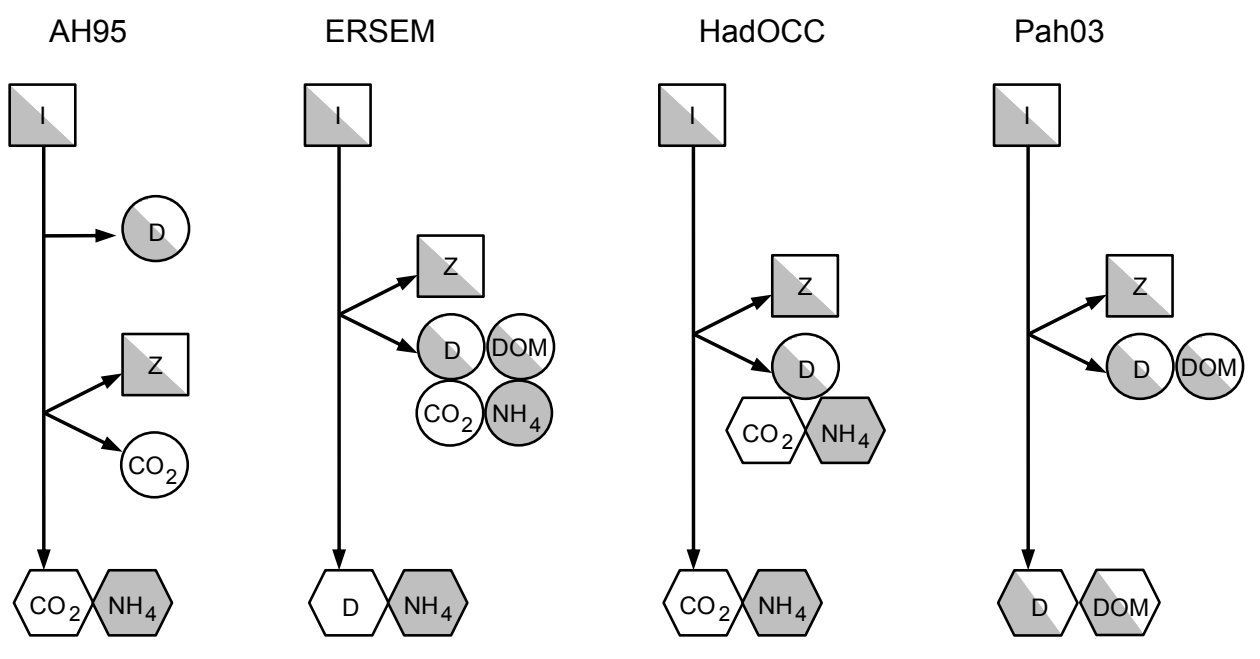

Figure 1 
Click here to download Figure(s): Fig2.pdf

a) Nitrogen
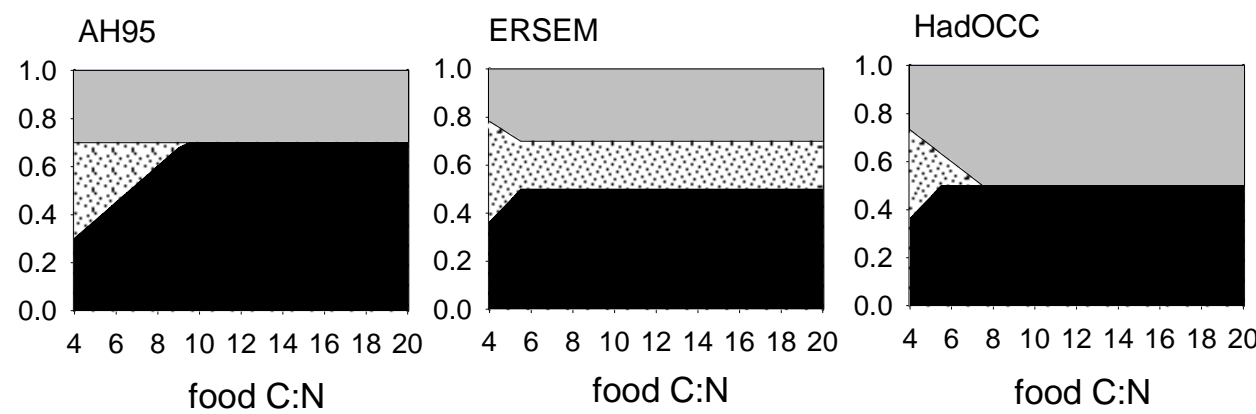

Pah08

b) Carbon


Figure 2 
a) Nitrogen



b) Carbon

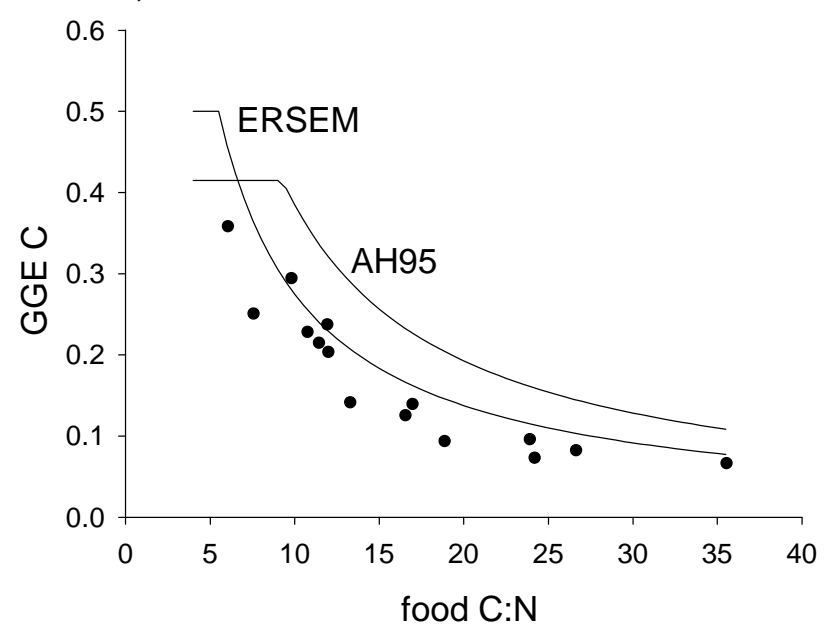

Figure 3 
Figures)

Click here to download Figures): Fig4.pptx

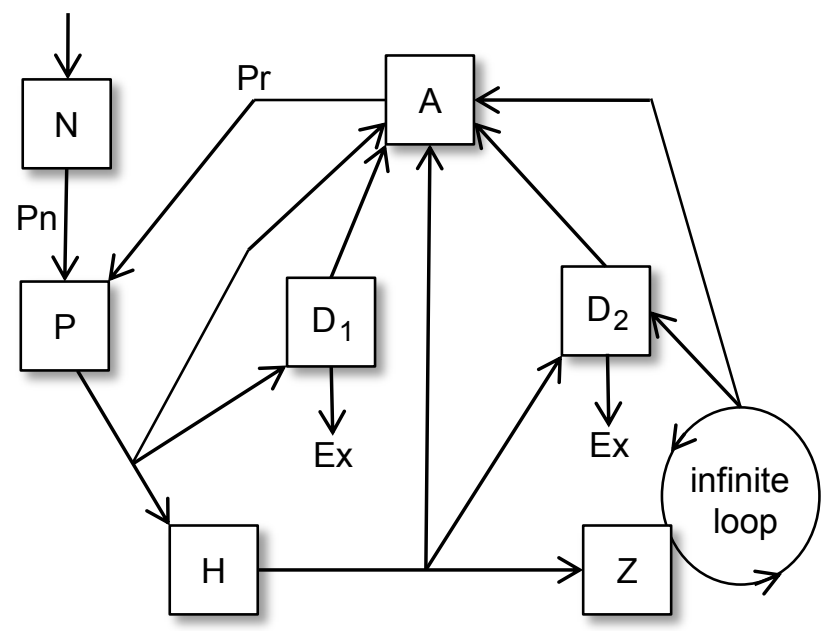

Figure 4 
a) Primary production

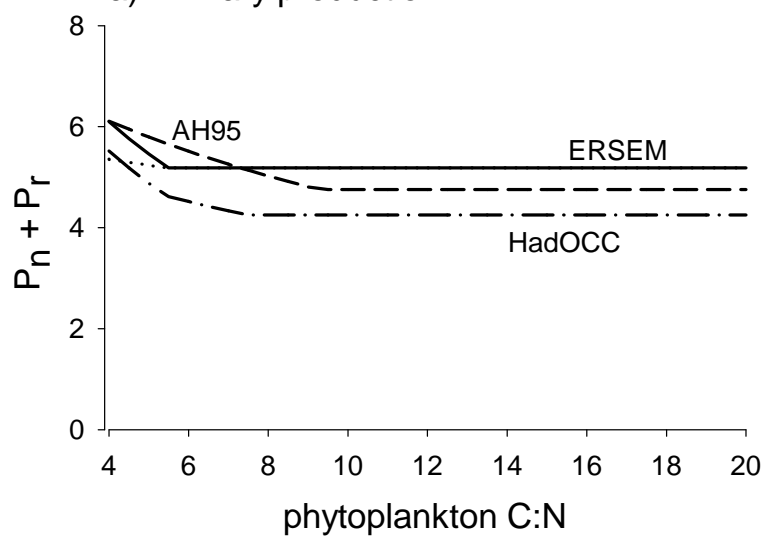

b) Production: herbivores

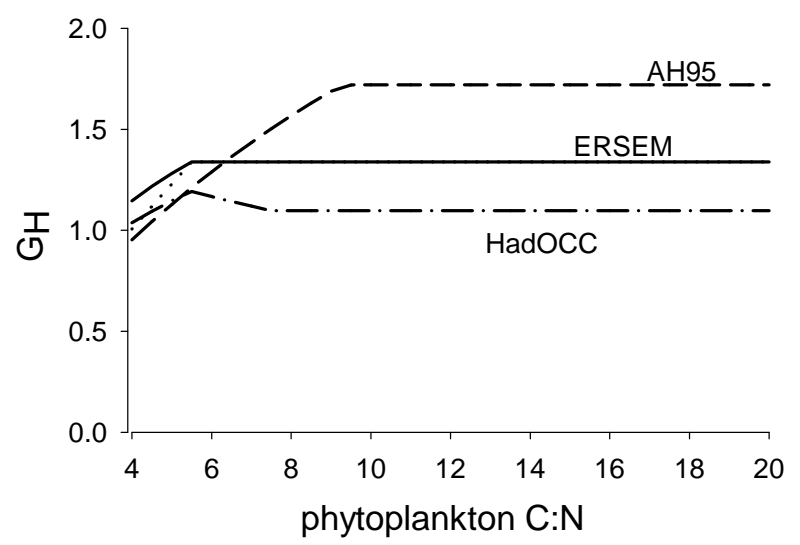

c) Production: carnivores

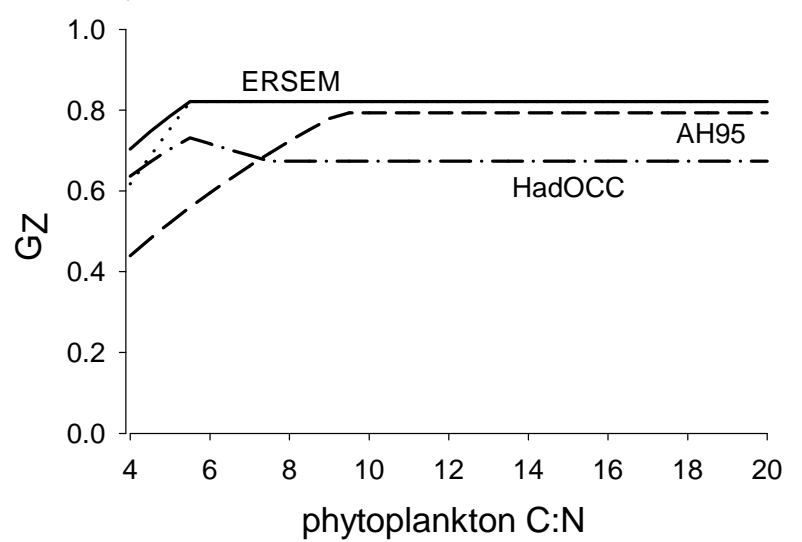

d) Export: $D_{1}$ (slow-sinking carbon)



e) Export: $D_{2}$ (fast-sinking carbon)

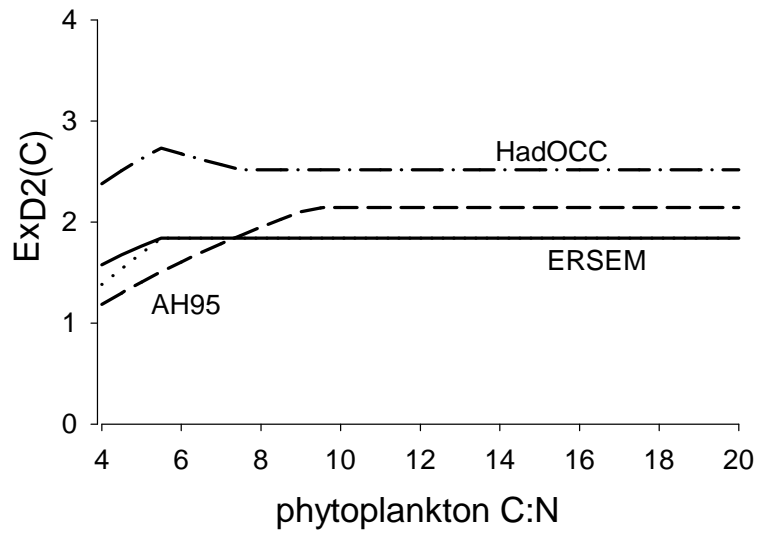

f) Export C/N (= total C export)

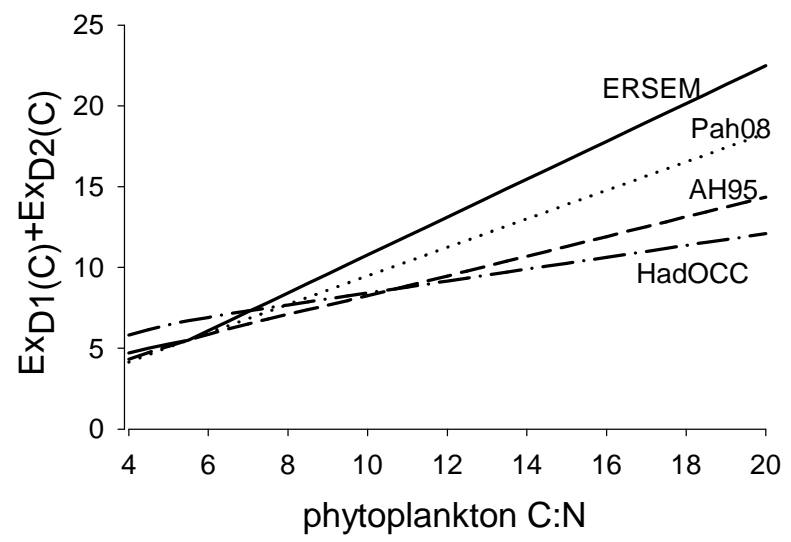

Figure 5 


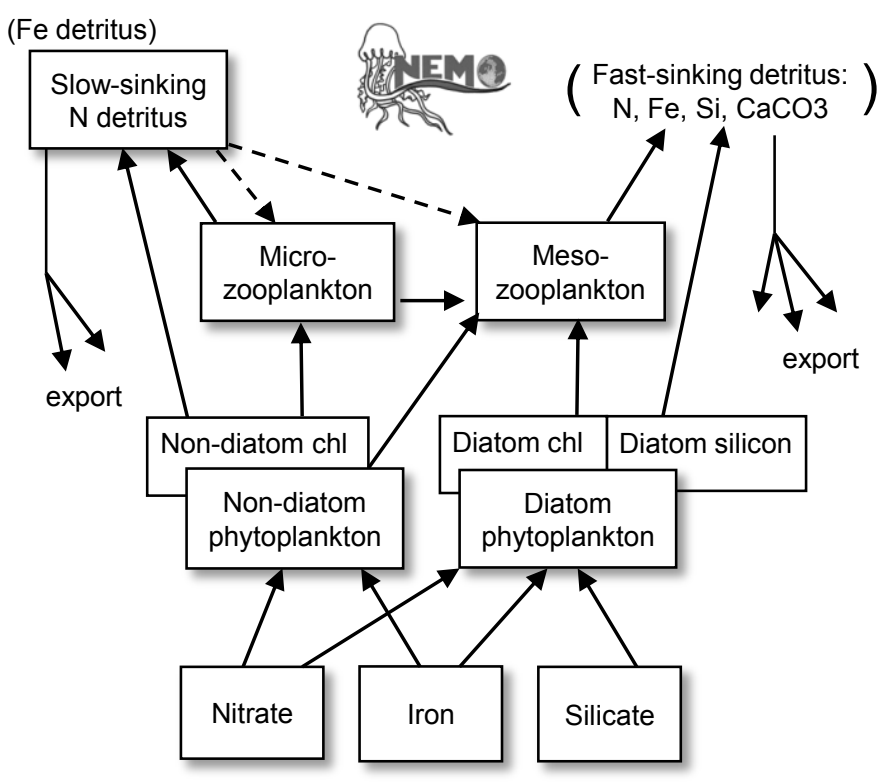

Figure 6 
AH95

a) Primary production, $\mathrm{g} \mathrm{C} \mathrm{m}^{-2} \mathrm{~d}^{-1}$
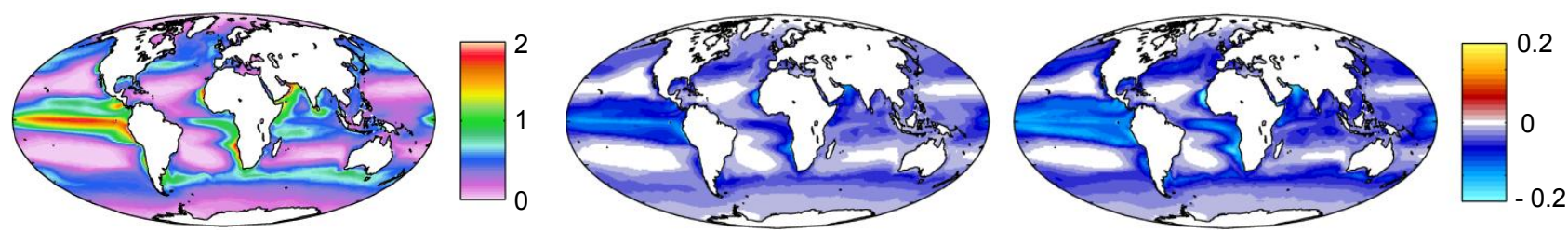

b) Surface phytoplankton, $\mathrm{mmol} \mathrm{N} \mathrm{m}{ }^{-3}$


c) Zooplankton production, $\mathrm{g} \mathrm{C} \mathrm{m}^{-2} \mathrm{~d}^{-1}$
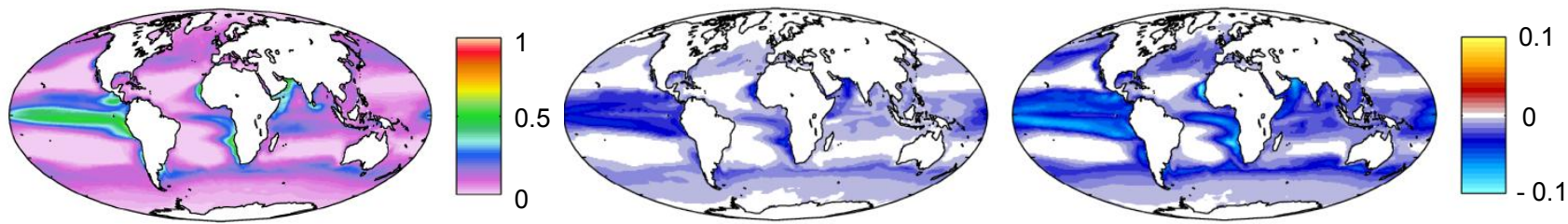

d) Surface zooplankton, mmol $\mathrm{N} \mathrm{m}^{-3}$


e) Detritus flux at $100 \mathrm{~m}, \mathrm{mmol} \mathrm{N} \mathrm{m} \mathrm{m}^{-2} \mathrm{~d}^{-1}$


Figure 7 